\title{
eBay in the Economic Literature: Analysis of an Auction Marketplace
}

\author{
Kevin Hasker • Robin Sickles
}

Published online: 25 August 2010

(C) Springer Science+Business Media, LLC. 2010

\begin{abstract}
This survey brings together theoretical and empirical questions that have been addressed in the economic literature on eBay, focusing on understanding the behavior of buyers and sellers. We discuss several puzzles of bidder behavior and the explanations that have been put forward by the literature for each. We then discuss structural estimates of bidder behavior and measuring the consumer surplus derived from eBay. We then try to understand why there are so many selling formats being used simultaneously, and then focus on the critical decision variables for a seller in an eBay English auction. Finally we analyze how trustworthy eBay sellers are on average, and whether the feedback system provides strong incentives for good behavior.
\end{abstract}

Keywords eBay · Online auctions · eBay consumer surplus · English ascending auctions

\section{Introduction}

In September of 1995 when Pierre Omidyar, the founder of eBay, auctioned off a broken laser pointer on his website he started a commercial revolution. Auctions have long been hailed by economists for their power to discover prices, but the primary obstacle in their widespread use was the cost of gathering bidders. Internet auctions overcome this critical problem. Three years later, in 1998, the gross fourth quarter

\footnotetext{
K. Hasker

Economics Department, Bilkent University, 06800 Bilkent, Ankara, Turkey

e-mail: hasker@bilkent.edu.tr

R. Sickles $(\varangle)$

Economics Department, Rice University, 6100, South Main Street, Houston, TX 77005-1892, USA

e-mail: rsickles@ rice.edu
} 
merchandise volume of eBay was $\$ 307$ million. In the fourth quarter of 2005, 10 years after eBay was founded, total sales were $\$ 12$ billion. ${ }^{1}$ In 2008 eBay bragged that if it was a traditional retailer, it would be the sixth largest (measured by sales volume) in the United States; and in the third quarter of 2008 it had negative growth for the first time in its history. eBay now operates in 29 countries, selling everything from Cold Mountain (the book, the DVD, and the mountain) to marbles.

Since eBay was the first Internet auction site, it has always benefitted from the network economies of a marketplace: Buyers want to go where the most sellers are; sellers want to go where the most buyers are. This simple logic made it unlikely that a second general auction website could be as successful, and indeed none have been. Both Yahoo! and Amazon launched competing websites in 1999. In 2007 Yahoo! officially closed their auction website in the United States and Amazon's auction website quietly stopped operating at around the same time. Yahoo! still operates in Asia and other areas, but they have ceded the US to eBay.

In the US the only successful competitors seem to be niche auctioneers or companies that offer auctions as a service. Thus, this survey comes at an interesting time in the history of online auctions. With the closure of eBay's competitors and the first quarter of negative growth around a year removed, eBay appears to have entered what could be considered a "mature" phase for the online auction marketplace.

So what does eBay look like? eBay was founded on Beanie Babies and other collectable items; indeed a public relations manager fabricated a story that the founder started eBay in order to help his fiancée trade Pez Candy dispensers (Cohen 2002). While it is undeniable that collectibles are still the most popular category on eBay, the second most popular is clothing. eBay used to be a marketplace for used goods; now fully $47 \%$ of eBay listings are classified as new. Many items that are sold on eBay are inexpensive, but it also has a thriving real estate category with around 3,000 listings, and eBay Motors lists over 60,000 cars and trucks for sale. In its 2008 annual report, eBay Motors points out that a Ford Mustang is sold every $26 \mathrm{~min}$. One can buy anything from antique tractors to Blu-Ray disc players, and there are millions of items sold for which shipping and handling costs exceed the sales price, while at the same time real estate is sold for millions of dollars.

eBay no longer is exclusively an auction website. eBay offers its sellers several different methods to sell items. The seller can use either a fixed price (Buy it Now, abbreviated $\mathrm{BiN}$ ), bargaining (Buy it Now or Best Offer, abbreviated $\mathrm{BiN}$ oBO), or an auction. If the seller uses an auction and sells only one item, then the format is essentially that of a traditional English auction with a hard closing time. In this format, the seller can also include a BiN price, where a potential buyer may either bid in the auction or accept the buy price and win the auction. If he bids and his bid is above the secret reserve price (if there is one), then the BiN option disappears, and the selling format continues as an auction. If the last bid is still below the secret reserve price, the BiN option continues to be available. It is important to note that before 2003, when the fixed price selling format was first made available on eBay, many eBay sellers were setting the first minimum bid equal to the BiN price, which turns the format into

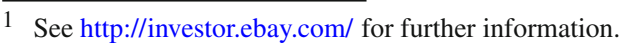


a fixed-price selling format. Often, however, the minimum bid is set below the BiN price, in which case a $\mathrm{BiN}$ auction combines features of both an auction and fixed-price selling.

If the seller uses an auction and sells multiple items, then he must use a "Dutch" auction. This is not the traditional Dutch auction in the economics literature; instead it is a multi-unit auction where bidders bid a number of units and a price per unit. The $\mathrm{BiN}$ selling format ${ }^{2}$ uses a traditional fixed price. If the buyer chooses the option "or Best Offer", this will allow personal negotiations between the buyer and the seller. In some categories the seller can also place traditional classified ads. In this way the seller advertises the good with a fixed price on eBay, but the transaction takes place outside of eBay, and the seller does not have access to eBay services such as Feedback and Problem Resolution. Fixed-price sales of all varieties make up $42 \%$ of the gross merchandise value of goods sold on eBay but $73 \%$ of the listings. Auctions (almost exclusively English Auctions) make up only 12\% of the listings but $58 \%$ of the sales. ${ }^{3}$

Clearly eBay is of interest to economists mainly because it is a new and revolutionary trading method. However, it is also a tremendous data resource. For example, if one wanted to analyze English auctions, information on the buyer, the seller, all bids placed, and information about the bidders for the last month can be obtained from eBay's website. There were 3,170 Ford Mustangs that were listed on eBay in February of 2009. Of course one might find Ford Mustangs to be too heterogenous. Perhaps new Blu-ray players are of more interest. In a recent search we found 2,384 items that closed in January 2009, of which approximately $80 \%$ were sold.

One can also find items whose values are almost completely determined by resale, or common value items such as US mint and proof coin sets (834 closed in January 2009); this market is analyzed in Bajari and Hortaçsu (2003a). One could also examine private value items such as music CDs (480,758 new CDs that were listed in 1 month were analyzed in Nekipelov 2007). One could also track sellers longitudinally (like Cabral and Hortaçsu 2010) and horizontally by using a seller-specific search. One can find all the items on which a bidder has bid in the last month, as well as the complete feedback history of both sellers and buyers. One also can generate a unique dataset from eBay. Katkar and Reiley (2006) conducted a field experiment and Bapna et al. (2008) offered a sniping program to eBay bidders in order to gather data. Garratt et al. (2004) recruited eBay bidders for an Internet experiment on second-price auctions.

Before beginning our review we would like to mention several other literature reviews and an early survey of the eBay market. In 1998 Lucking-Reiley (2000) provided an accurate overview of the eBay market in the early days of its development. Bajari and Hortaçsu (2004) is also an excellent survey of the early literature. Ockenfels et al. (2006) is a thorough and detailed analysis of electronic auctions, focusing especially on the experimental literature.

In contrast with these papers, we will not spend much time analyzing market design. eBay is reluctant to change their format since they face substantial opposition from

\footnotetext{
2 Notice that here we discuss BiN as a selling format, not as an option in an auction.

3 For detailed information about different selling formats, see http://pages.ebay.com/help/sell/formats. html.
} 
users each time they do and furthermore, they seem more inclined to listen to their buyers and sellers than to economists. Our survey will focus on understanding the behavior of buyers and sellers on eBay.

We begin with a brief overview of the eBay market. Section 3 next discusses buyer behavior on eBay, primarily focusing on auctions. We discuss several puzzles of bidder behavior and the explanations put forward by the literature for each. We then discuss structural estimates of bidder behavior and one of the most interesting outcomes of structural estimation: measuring the consumer surplus derived from eBay. We then switch to the more complex problem of seller behavior in Sect. 4. We begin by trying to understand why there are so many formats being used simultaneously, and then focus on the critical decision variables for a seller in an eBay English auction. Finally in Sect. 4.3 we analyze how trustworthy eBay sellers are on average, and whether the feedback system provides strong incentives for good behavior. We then summarize and discuss some general directions for future research in Sect. 5.

\section{The eBay Market}

One of the more striking features of the modern eBay platform is its remarkable diversity and the large volume of goods for sale. While it is still the case that much of eBay's volume is composed of used, low price, and collectible items, there still are millions of items listed everyday that do not fit this category. The second largest category is clothing, and $63 \%$ of those listings are classified as new. eBay motors had over 60,000 cars and trucks listed. In 2004, Andrews and Benzing (2007) found 600 auctions for Honda Accords in a three week period. There were 1,045 listings in January of 2009. eBay claims 100 million items on sale worldwide at any given time. In a cursory survey on the veracity of this claim, we found 78 million on sale at eBay.com alone.

eBay is no longer primarily an auction website. Overall only $12 \%$ of their listings in our quick survey were auctions, but this adds up to 9.4 million auctions. A vast majority $(69 \%)$ of the listings on eBay are store inventory, the stock of items from eBay stores. Table 1 provides information on the relative importance of the selling formats by category. Sellers can pay a fixed fee to have an official eBay website list of the items that they have for sale, and eBay store owners also can list items normally on eBay and pay a reduced fee for those listings.

Currently sellers have three different methods of selling their items: they can use an auction, fixed price (Buy it Now, BiN), or bargaining (Buy it Now or Best Offer, $\mathrm{BiN}$ oBO). It is unlikely that this list of options will decrease in the future, but it could increase. For example the auction format when the seller wants to sell multiple units (the "Dutch Auction") seems to no longer be used frequently, but it is still an option.

In a few categories there are two types of bargaining available. The sellers can either use $\mathrm{BiN}$ oBO or they can use a traditional classified ad, with the final sale and negotiation taking place off eBay. ${ }^{4} \mathrm{BiN}$ oBO allows standard, and unfortunately

4 Classified advertisements can be placed in the (sub)categories: Businesses for Sale, Trade Show Displays, Real Estate, Specialty Services, Travel, and Everything Else. See http://pages.ebay.com/help/sell/ adformatfees.html. 


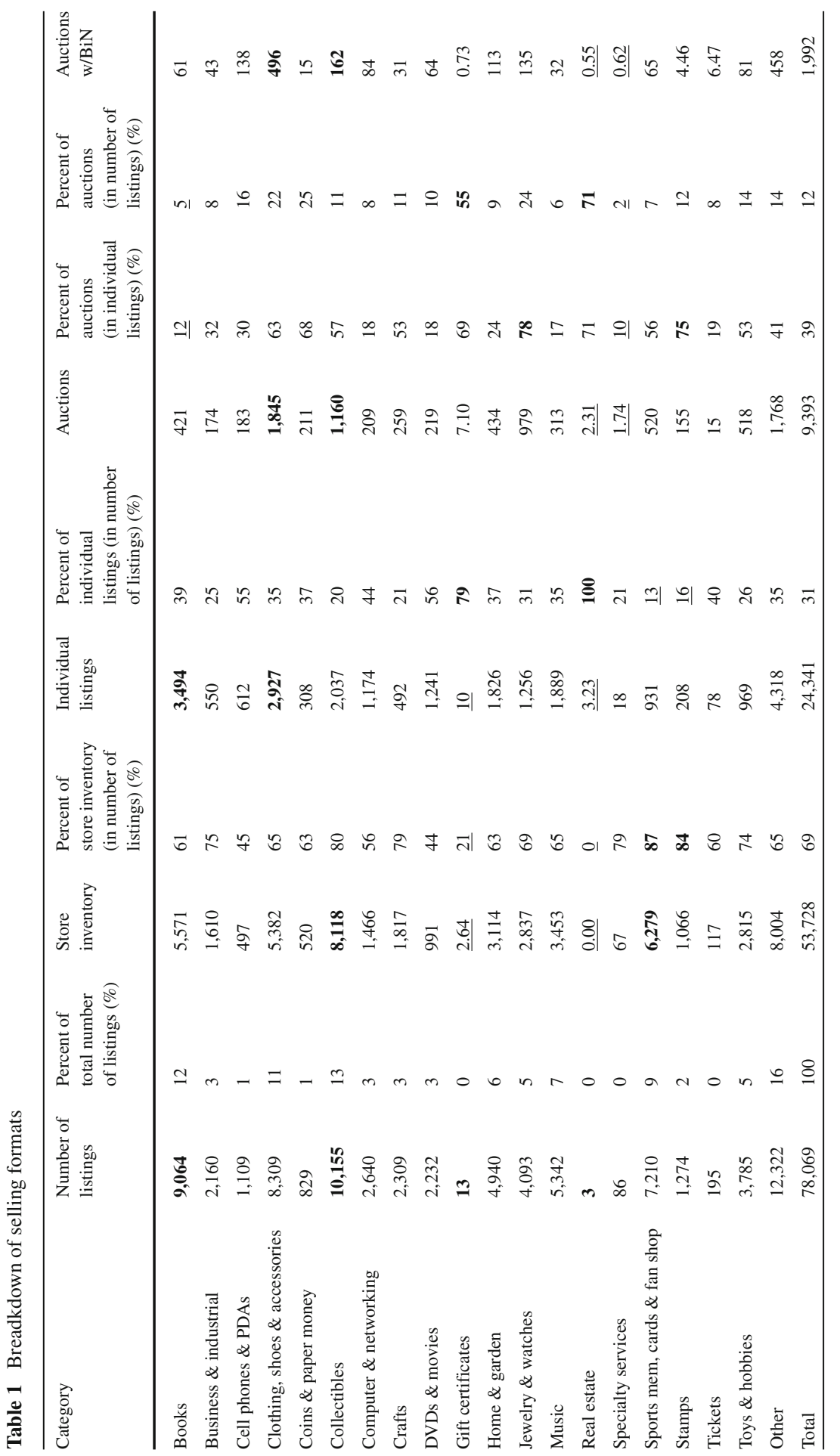




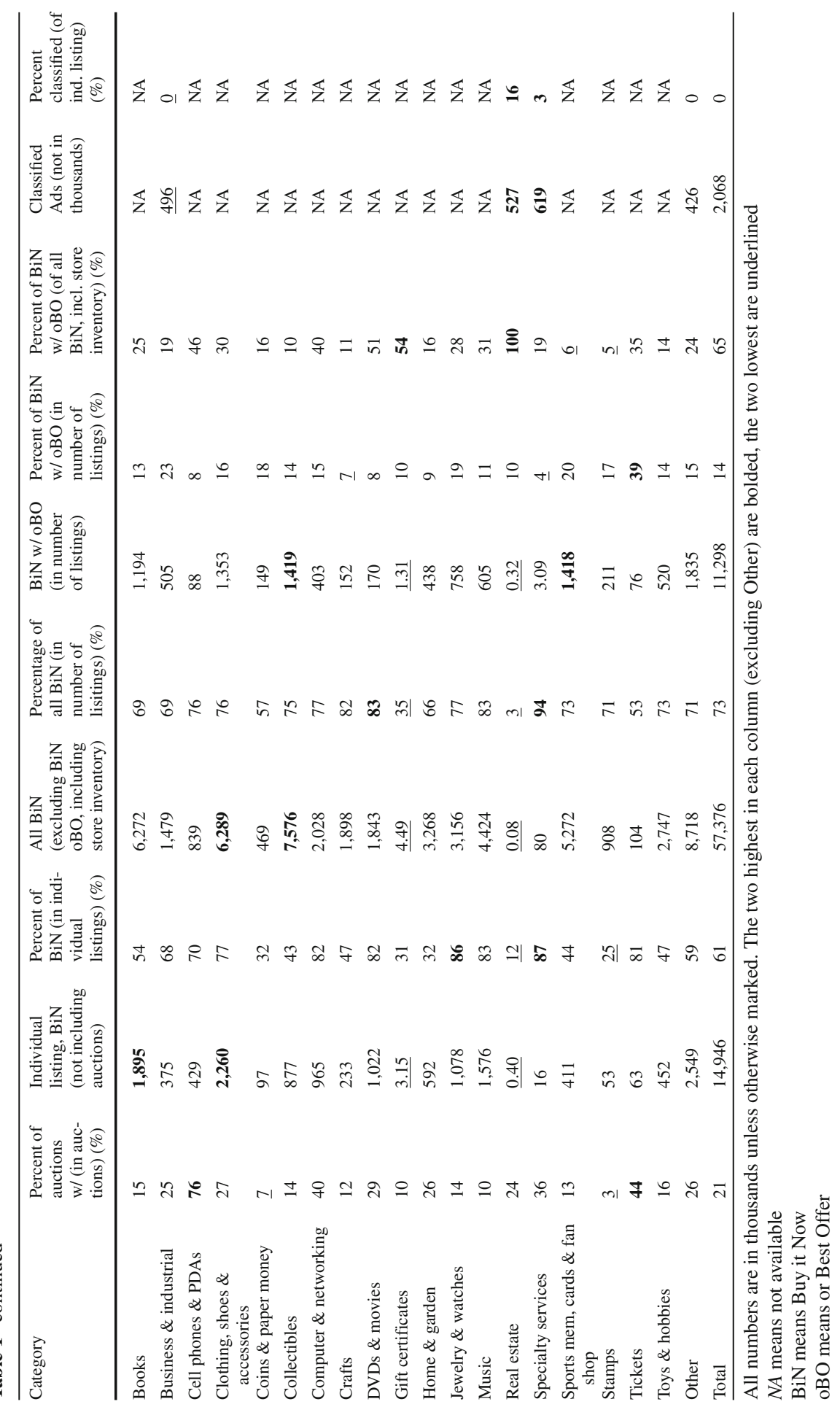


private, bargaining between the seller and the bidder regardless of whether the seller has one item or multiple items. The buyers make offers, and the seller can accept, reject, or make a counteroffer. Generally the offers and sales history only show that offers were accepted or expired though for a while the highest rejected offer is also recorded. The privacy of behavior in this market makes analysis much more problematic than in auctions since of course buyers also do not have access to this information.

This type of selling seems to have replaced the multi-item auction on eBay known as the "Dutch" Auction. After trying different keyword searches for Dutch Auctions, we were able to find only 2,238 auctions, representing .024\% of all auction listings. "Dutch Auction" seems to be a slang for either not knowing what you will get or that there is more than one item available. Other listings (usually from very experienced sellers) had general statements that included information about Dutch Auctions. Usually these warned bidders about the differences between Dutch Auctions and regular auctions. In the Dutch Auction there is no proxy bidding, and the bidder bids a price per unit and a number of units. The price is set by the lowest winning bid. The lowest winner has a right to refuse delivery if he does not get the quantity he demanded. This means that even if a bidder wants one unit, then she must bid as if she is in a first price (pay your bid) auction; and if she wants more than one, she has an incentive to decrease her demand so that she is less likely to set the price. It is no wonder that some sellers have general warnings about such auctions, as they most likely have had many complaints about not understanding the rules. Indeed many sellers do not seem fully to understand the rules either, since $22 \%$ of the auction listings we checked were for one item. Since a Dutch Auction must be for two or more identical items, it is clear the sellers themselves do not know what a Dutch Auction is.

If sellers choose to use an auction and have only one item to sell (or choose to use multiple single-item auctions), they can use a type of auction that is like a traditional English auction but with a hard closing time. In these auctions bidders can place their maximum willingness to pay (or less than that if they want to revise their bid in the case of being outbid) into a proxy bidding program. The proxy bidding program then raises the current winning price until it is either the second highest bid plus a bidding increment or the highest bid, whichever is smaller.

Throughout the rest of our survey, unless we specifically mention otherwise, we will focus on single-item auctions. These auctions may last from 3 to 10 days. They can have an open reservation price which is called a "first bid," and a second, secret reservation price (called simply a "reservation price"), and they can also have a "Buy it Now" option that disappears once a bid is placed that is higher than the first bid or the secret reservation price. ${ }^{5}$ When a bidder bids he can observe the value of all bids up to that time, except the last bid by the highest bidder. The bidder places a bid using the proxy bidding program. This amount can be the current winning price plus a bidding increment or any higher value. The program then raises the price until either

\footnotetext{
5 eBay has recently begun experimenting with a plan that extends the length of time that the BiN option is available: specifically, until the auction price is $50 \%$ of the BiN price. eBay started this test in October of 2007 in Parts \& Accessories, Tickets, Clothing, and Cell Phones; and to the best of our knowledge it continues to this day. See http://forums.ebay.com/db1/topic/Auction-Listings/Longer-Lasting-Buy/2000449591 for more information.
} 
the new bidder is the only one willing to pay that price, or the new bidder loses to the current high bidder. The one difference between this and a standard English Auction is that, on eBay, auctions have a hard closing time. While this has been questioned in the academic literature, buyers and sellers appear to like it since it provides more certainty to the parties in the transactions. In an online auction that would replicate the traditional English Auction format, the length of the auction would need to be changed to last 5-10 min longer each time someone places a bid, and thus the buyer and seller would never know when the auction would end. ${ }^{6}$

The seller also has other options to increase the visibility and the salability of his item; eBay has tutorials devoted to this subject. The tutorials encourage sellers to use pictures, detailed descriptions, and to have long titles that can turn up on many different searches. The seller can purchase the right to be a "featured item", which means that the item will always appear at the top of any relevant search. The seller also can advertise that he has free shipping and is willing to accept payment by PayPal.

Seller fees are based primarily on the first bid or secret reserve price and the final sales price. For auctions, the insertion fee is essentially trivial, from 10 cents to a high of $\$ 4.00$ (if the higher of the first bid or secret reserve price is $\$ 500$ or more). The final sales fee is higher, and decreasing as the final sales price increases. Currently, for the first $\$ 25$ of the sales price the seller is charged $8.75 \%$ (5\% in Lucking-Reiley 2000); for any remaining amount above $\$ 25$ and below $\$ 1,000$ the seller is charged $3.5 \%$ (2.5\% in Lucking-Reiley 2000); and for every higher dollar the seller is charged $1.5 \%$. While still dwarfed by the fees from traditional auctioneers like Sotheby's (where the charge on the final sales price can be as high as 35\%) the $42 \%$ increase in eBay's fees since 2000 shows that it is taking advantage of its market position. For fixed price sales the insertion price is at most 15 cents, but the final sales fee is higher. The highest percentage fee is for Books or DVDs that are sold for less than \$50, where the final sales fee is $15 \%$ of the price. The fees for extras are generally fixed. For an auction to be a featured item the cost is $\$ 24.95$. $^{7}$

When deciding what type of mechanism to use, the seller has a plethora of information available. All listings (including unsold items) are available on eBay for 1 month after the listing is closed. This data base is easily searchable, so the seller (or the buyer) can often find other auctions and fixed-price sales for the exact item being considered. One can also find all other listings by a given seller, and the purchases of a given buyer in the last month. The complete feedback history of both buyers and sellers also is public information.

The feedback of buyers and sellers is a numerical evaluation from the point of view of the seller and buyer. After a transaction has been completed, the buyer and seller may rate the other party as good ( +1 to feedback), neutral ( 0 to feedback), or negative ( -1 to feedback). Since 2003 eBay also has posted the percentage of positive feedbacks on the auction web page. Along with the numerical rating, people are encouraged to leave text comments and a Detailed Seller Rating, which rates the seller in five

\footnotetext{
6 Amazon had this feature on their auction website; and as can be seen (at: http://glinden.blogspot.com/ 2006/04/early-amazon-auctions.html) this has caused complaints.

7 All of these fees are current as of January 2009.
} 
different categories (Item as Described, Communication, Shipping Time, and Shipping and Handling Charges) from 1 to 5.

eBay claims to be constantly working to improve the feedback system, and currently eBay displays the raw feedback rating and the percentage of positive feedback in the last year on all auction pages. The eBay web pages also contain icons that indicate a seller's and buyer's feedback, and have a special category, power seller, that indicates a given seller has a high volume of sales and a high feedback rating. Clicking on someone's feedback score takes one to a page that shows the number of positive, negative, and neutral feedbacks in the last month, the last 6 months, and the last year. Unfortunately, all reporting depends on voluntary action by the buyers and sellers, so there is selection. Resnick and Zeckhauser (2002) report that only $52.1 \%$ of buyers leave feedback. In 2008 eBay no longer allowed sellers to provide negative feedback to bidders in an attempt to improve the response rate, an important factor in eBay auctions, since before this revision feedback was potentially subject to revenge strategies. Cabral and Hortaçsu (2010) report that negative feedback has a $40 \%$ chance of being returned, and that neutral feedback has a $10 \%$ chance of retaliation.

Clearly a researcher or analyst of eBay auctions has a wealth of data concerning common value items, private value items, and mixtures of the two. Goods sold in private value auctions are valued by the utility that the consumer will enjoy from consuming or owning the good. ${ }^{8}$ Private value items may be resold once (many items on eBay are used), but they are almost never resold again. Examples are clothing, electronic items, and DVDs or CDs. Goods sold in common value auctions are items for which the true value is the same for all bidders, but bidders may have different information about this value. An item rarely has a pure common value. A characteristic of a pure common value item is that its value is based primarily on resale. Collectible items (approximately a third of all items on eBay) are generally considered common value. These include trading cards (Katkar and Reiley 2006) or coins (Bajari and Hortaçsu 2003a). Other examples of common value items are those purchased only for their commercial value. These include mineral rights (Wilson 1977) and oil fields (Hendricks et al. 1987), which are not commonly sold on eBay.

Bajari and Hortaçsu (2003a) develop tests for common values in collectible coins. A hallmark of common value items is the "winner's curse", wherein the winning bidder will be the most optimistic bidder, and thus is likely to be too optimistic. Based on implications of the winner's curse and a suggestion in Paarsch (1992), they regress the value of the winning bid on the number of bids. Paarsch (1992) points out that if the winner's curse is present, then more bidders would imply that the winner is more optimistic, and this will lead bidders to lower their bids more. For example, if there is only one bidder, then the winner is simply that bidder, and the winner's curse is non existent so the bidder should just bid his value. If there are ten, then the winner is more optimistic than nine other people, and thus his estimate is likely to be too high, and in equilibrium this will lead bidders to lower their bid. Bajari and Hortaçsu find the expected negative coefficient, which implies that there are common values, as one should expect with collectible coins since a priori analysis suggests that the

8 Whenever we use private values in the text the reader should understand that the private values are also independently distributed. 
coins should have common values. Their test assumes that all bids are the bidder's true estimate of the item's value. Since bidders bid multiple times on eBay, this may not be true, because the bidder may be planning to increase her bid at a later time, but then may reevaluate her bidding strategy and discover that the item is not worth the higher planned bid. This would result in a negative coefficient even in a pure private values environment. ${ }^{9}$ In order to be executed properly, the test should only use bids that have been submitted in the last few seconds of the auction, and the number of bidders should be the number of bidders who submitted bids prior to the given bid.

The primary reason a good on eBay might have a common value component is asymmetric information. This is a significant problem on eBay, which has instituted the feedback system to help encourage both buyers and sellers to provide information accurately. eBay encourages participants to use PayPal (which is owned by eBay), where the payment is made only after both parties indicate that they are satisfied with the transaction. Despite these measures, a substantial amount of information is not provided, and this is particularly problematic for used goods.

One of the recurring and common problems on eBay is that sellers may not provide a detailed description of the item for sale. Yin (2006) used surveys to test whether used computers have a common value component or not. Since computer technology is advancing at such a high pace, a priori one would expect the resale value of computers to be very low, and thus one would classify computers as goods with private value characteristics. However, these are used computers, and many are sold based on rather incomplete descriptions leading to substantial uncertainty about their value. Yin was able to download the item description from eBay, expunge it of all seller related information, and then take a survey of the items' values. She found that the variance of the survey respondents' estimated values had a significant negative correlation with the sales price, indicating that more uncertainty was associated with a greater discount.

However, the average estimate generated by her survey was almost twice the average sales price. It is theoretically possible that the proper sales price is half the value due to the winner's curse, but it is unlikely. The more likely explanation is that survey respondents had no incentive to conduct their own research on the item and thus had incomplete information. However, even if the survey respondents had much worse information than the bidders, the correlation does suggest that the bidders also had incomplete information. The potential for asymmetric information is one reason many empirical researchers examine relatively new and standardized goods. Since each sale must involve some asymmetric information, researchers must be careful to ascertain how much asymmetric information is present and whether it is an important factor in determining the value.

\footnotetext{
9 Assume that in every auction only two bidders bid 1 and all other bidders bid 0 . In an auction with $n$ bidders, the average number of bids observed by any one of the bidders who bid once is $(2-1) /(n-1)=1 / n-1$. Since we do not observe the highest bid, only that it is higher than the second highest bid, we can not use the highest bid in these calculations. In the case where the average bid is observed by an outsider, the formula would be $2 / n$.
} 


\section{Buyer Behavior}

There has been relatively little analysis of how the buyers choose among the three different eBay auction formats. However, there has been extensive analysis of the choice within a given mechanism. Most of the viable theoretic explanations of why buyers would buy at a fixed price instead of an auction rely on risk aversion (Mathews and Katzman 2006; and Reynolds and Wooders 2009). A less analyzed but probably important factor is the cost of keeping track of auction bids and completing a transaction at a time removed from when one bids. As the New York Times online shopper says, "...in a busy life it can be too difficult keeping track of the auctions you have bid in ...". 10

In this section we will treat fixed price buying as an outside option for the type of format for which eBay is famous: single-unit auctions. The optimization problem for a bidder in such an auction is relatively straightforward: When buyers come to eBay, they can search for the item in which they are interested and will see an array of listings. The bidder can sort the list based on time to closing, time left, and highest or lowest current price (including shipping and handling) and can choose an auction in which to bid or a listing from which to buy.

On the asumption that the bidder finds an auction (with up to 10 days left in which to bid), he can bid the current price plus one bidding increment. However, this will only waste time because eBay has a proxy bidding machine into which the bidder can enter the highest bid that he is willing to pay. This amount is kept confidential from other bidders and the seller. The proxy bidding program compares his bid to those of the other bidders; then it will increase the current winning price (which is observable to everyone) until either he is the sole bidder willing to pay that price, or he has been outbid by someone else. Once he has been outbid, he can choose a different auction in which to bid or he can bid a second time in the same auction. The bidder can revise his bid anytime by bidding a higher amount, but he cannot lower it. This bidding system allows bidders to avoid coming back to re-bid every time that another bid is placed. ${ }^{11}$

Optimizing in this environment is relatively straightforward from the perspective of classical economic theory: If the auction that a bidder chooses to enter is considered in isolation, the bidder can bid any finite number of times before the auction ends. If it is a pure private values auction, then since no one else's bid depends on his bid, he could bid at any time. If the auction has common values, such as the mineral rights model in Wilson (1977), then the problem is slightly harder. If other bidders believe an item is valuable (and bid large amounts), a given bidder should increase his bid. Bajari and Hortaçsu (2003a) show that this implies that everyone should bid at the end of the auction. More generally, most goods are a mixture of private and common values, and bidders have affiliated utility functions (Milgrom and Weber 1982). With these goods the key characteristic of common value auctions remains. Thus, we can be certain that the insight in Bajari and Hortaçsu (2003a) generalizes, and one should

\footnotetext{
10 See ONLINE SHOPPER; Here's a Concept: Fixed Prices at eBay. The New York Times, July 5, 2001. http://query.nytimes.com/gst/fullpage.html?res=980DE6DE1638F936A35754C0A9679C8B63.

11 Please see the FAQ's page of eBay for further information about proxy bidding: http://answercenter. ebay.com/thread.jspa?threadID $=900039195 \&$ tstart $=0 \& \bmod =1163650373615$.
} 
bid at the last possible time in the auction. What should one bid? In eBay auctions one should just bid what one thinks the item is worth. This was first shown in the private values environment by Vickrey (1961), as well as in the most general environments by Milgrom and Weber (1982). ${ }^{12}$

From the perspective of economic theory, the complex behavior of bidders on eBay presents an intellectual challenge: While theory does predict that without loss of generality the bid should come towards the end of the auction, bids are often submitted so late that they sometimes don't get in. This is a practice called sniping (Roth and Ockenfels 2002). While theory predicts that there should be only one bid, bidders frequently bid more than once, a practice referred to as incremental bidding. Bidders are often observed to bid large amounts early, a practice either called squatting (Ely and Hossain 2009) or jump bidding (Avery 1998). Explanations put forth for these practices center around the basic point that eBay is not one auction in isolation but rather a competitive auction marketplace.

In the remainder of this section we discuss these three puzzles of bidder behavior. We then outline various methods to estimate the bidder's behavior. We end the section with a discussion of how to measure the consumers' benefit from these auctions.

\subsection{Sniping (Last Second Bidding)}

One of the most celebrated puzzles in bidding behavior is last second bidding, called sniping. Roth and Ockenfels (2002) found in a survey that $37 \%$ of final bids are submitted in the last minute and $12 \%$ in the last $10 \mathrm{~s}$, and similar results have been confirmed by many other surveys. The puzzling thing about this behavior is that it is possible that such bids are not received before the deadline, so the bidder loses the auction even if he wanted to place a winning bid. ${ }^{13}$ eBay formerly communicated this possibility directly to bidders on a web page that explained to bidders that, if they were upset because bids did not get in, then they shouldn't snipe.

Perhaps the simplest explanation for sniping behavior is that there are partial common values. Bajari and Hortaçsu (2003a) show that this would induce last minute bidding on eBay and that the last minute bids would not necessarily have to be entered in the auction with certainty. Recall that in a pure private values environment the bidder is indifferent on bid timing and thus, even if there is a small element of common value for the item, it would be sufficient to induce the bidder to bid at the last second. Nekipelov (2007) argues that partial common values are natural in eBay auctions because of common uncertainty about market conditions. He further notes that even if a good has only private value, the number of bidders may still be determined by the "visibility" of a given auction. This market specific variable would be unknown but estimated by the bidders and would induce a common value to the auction, which in turn would provide enough of an inducement for sniping behavior.

\footnotetext{
12 We note that, as in Sailer (2006), this may include the continuation value of the bidder if he does not win this auction.

13 No one has ever documented how high the probability of a bid not getting in is. It is probably less than $1 \%$, and probably is decreasing as eBay perfects its software.
} 
Ockenfels and Roth (2006) put forward another simple explanation: They point out that sniping is simply a best response to incremental bidding. If some bidders bid incrementally, increasing their bid by the bidding increment until they are the high bidder, then it is always best to bid when those bidders cannot respond, which would occur during the sniping window (the last minute or seconds of a hard closing auction during which the bidders with the aim of sniping place their bids). Wintr (2008) shows in a field experiment that more incremental bidding leads to more sniping, which is consistent with this hypothesis. Ely and Hossain (2009) also confirm the simple explanation of Ockenfels and Roth (2006) and verify that sniping does have a small empirical benefit in field experiments. Peters and Severinov (2006) have shown that incremental bidding can be part of an equilibrium in an auction marketplace. In that equilibrium incremental bidding is used to sort bidders among the auctions; if two bidders bid at the same time in an auction, then one moves elsewhere, and the current winner has not lost much since both parties only bid the increment. This explanation is simple and explains the observed phenomena.

One reason for the presence of sniping may be because the seller may engage in shill bidding. This is analogous to having a third party (or alternative identity) bid in the auction just to drive up the price. Engelberg and Williams (2009) show that eBay is especially well designed for a seller to enter shill bids. If the highest bid is less than a bidding increment above the second highest, the sales price is the highest bid, thus the shill bidder can bid apparently strange amounts, ending in 19 cents for example, and push the price up until the highest bid is revealed. For example, assume that the current price is $\$ 26$ and the current highest bid is $\$ 30$. If the shill bids are entered $\$ x .19$ for $x \in\{26,27,28,29\}$, then when the shill bidder bids slightly more than $\$ 29$, the current price will be $\$ 30$ and the shill bidder can stop increasing his bid. Clearly, a simple best response to this type of strategy is to snipe.

One of the more well known explanations for shill bidding was put forth in Roth and Ockenfels (2002) "snipe or war" strategy. In a pure private values environment, bidders can agree to wait until the sniping window before placing their bids. If all bidders follow this strategy, then competition will be reduced since some bids will not be registered. However, to enforce this behavior one has to start a bidding war if a bidder bids earlier, which is the "war" part of the strategy. Gonzalez et al. (2009) show that these equilibria exist under very general conditions. While this strategy is theoretically possible, it is very complicated, and it is not clear how such a strategy could become common knowledge in a market like eBay. Furthermore, it is questionable if this would characterize an equilibrium, since bidders could leave the auction and bid elsewhere.

This led Gonzalez et al. (2009) to develop a general test for these types of equilibria. Their test is based on the observation that if bidders are using a snipe or war strategy, then auctions in which the final bid is placed early should be "war" auctions and be more competitive than auctions that end during the sniping window. One can thus test for the difference between the two distribution of bids; and in their empirical study of a large number of eBay computer monitor auctions, Gonzalez et al. find no significant difference in the two distributions. Wintr (2008) also confirms this result with a difference in medians test. Bajari and Hortaçsu (2003a) examine results from reduced form regressions that indicate that early bidding is not correlated with a high 
final sales price. Neither of the two latter tests hold for every snipe-or-war strategy, but the failure to confirm the hypothesis through the use of a variety of tests is informative. Equilibrium in the "snipe or war" strategy game relies critically on the uncertainty that is involved with a successful snipe. If it is certain that a late bid will be successfully entered, then sniping should disappear. In contrast, Ariely et al. (2005) conduct a laboratory experiment and find that if the sniping bid will be recorded with certainty, sniping actually increases.

One can estimate the benefit to sniping. Gray and Reiley (2004) found that the price was $2.54 \%$ lower when the experimenter bid with just $10 \mathrm{~s}$ left, but this was not statistically significant. Ely and Hossain (2009) found that sniping (bidding in the last $5 \mathrm{~s}$ of the auction) gives $1 \%$ more surplus when compared to bidding once early in the auction (squatting.) The bids were lower in Ely and Hossain (2009) than in Gray and Reiley (2004), and the Ely and Hossain data set is larger, possibly explaining the statistical significance of their results as well as reflecting more accurately the probability of winning given the bid. Neither study reported that the sniping bids failed to get into the auctions.

\subsection{Incremental Bidding}

One of the uncelebrated puzzles of bidding behavior is that bidders frequently bid multiple times. Instead of simply entering a true maximum willingness to pay, bidders increase their bid by small incremental amounts over time. Wilcox (2000) shows that the average bidder submits 1.5-2 bids, while Ockenfels and Roth (2006) report 38\% of bidders bid at least twice. This may seem counter-intuitive. For example, Bajari and Hortaçsu (2003a) show that in a common (or affiliated) values environment bidders should bid only once. Moreover, bid preparation does have a positive cost, and thus multiple bids are not costless. Indeed, Ockenfels and Roth (2006) refer to this behavior as "naive." Peters and Severinov (2006), however, show that it may be part of an equilibrium strategy. They analyze a simultaneous auction of many identical units of a private value good. Each bidder is assumed to have a unitary demand, and price in each auction is determined by the traditional English auction mechanism. Peters and Severinov show that there is an equilibrium in which bidders always use an incremental strategy and switch auctions (cross-bid) if another auction has a strictly lower price. Intuitively they use the incremental strategy to coordinate behavior. If two high value bidders are in the same auction, then one of them will switch to another one. One implication of the Peters and Severinov model is that a large number of bids would be expected rather than only a few. However, bid preparation cost in their model is zero.

Stryszowska (2005) provides an example of a two-auction game wherein no equilibrium exists when bidders do not bid early and in equilibrium everyone bids twice. It is likely that with more auctions some bidders would bid more often with high probability. Nekipelov (2007) finds that this is the case in a market in which values are private but there is an unknown market parameter about which bidders have heterogeneous information. This essentially makes the values of bidders affiliated, and incremental bidding is used to discourage entry by others. Whether those results obtain in a pure common values or a traditional affiliated values environment is unclear. Empirical 
evidence on whether bidders cross-bid is mixed. Tung et al. (2003) tracked simultaneous online auctions on identical consumer electronic items and found large price disparities. The arbitrage opportunities that this implies contradict the basic theory of Peters and Severinov (2006). In contrast, Anwar et al. (2006) collected data for CPU auctions and found that behavior was consistent with economic theory. Bidders tended to bid in the auction with the lowest high bid, and auctions that ended at about the same time had more cross-bidding. Furthermore, cross-bidders did well by their strategy and on average they paid 9\% less in a successful bid. Ariely and Simonson (2003) also found strong evidence of cross-bidding, and that when there were many similar objects on sale the reserve price had little impact on the final sales price. Further tests of this hypothesis would be helpful.

This type of behavior is problematic for empirical analysis. The reason is that in a private value environment if someone is bidding more than once, then clearly the early bid does not reflect the bidder's true value of the good. Thus, how do we know that the resulting price is equivalent to the bidder's value? Gonzalez et al. (2009) show that a bidder's last bid must be equal to his value if he believes it is possible to win. This guarantees that the sales price (the second highest bid) can be trusted. However, it is not clear how one evaluates other bids. In a common value environment bidders submit multiple bids because other bidders' bids revealed information to them, but then this means that their later bids must incorporate the information contained in other bids. It is not clear how one would analyze this type of bidding behavior in a structural model that lent itself to empirical implementation.

\subsection{Squatting or Jumping}

A strategy that has only come to note of late involves bidding a large amount early in the auction. This is similar to a type of strategy that is used in traditional auctions called "jump bidding" (Avery 1998). However, on eBay it serves a coordination role, so a new term is appropriate. Ely and Hossain (2009) refer to this strategy as "squatting."

With a jump bid the primary goal is to induce one's competitor to quit the auction. By bidding a large amount early in the auction, the bidder intimidates her opponents into dropping out. This traditionally has been used in pay-your-bid auctions, where one bidder can immediately raise the price far above the current level. As discussed in Gonzalez et al. (2009), the proxy bidding program that eBay employs prevents this behavior. In order for the size of a jump bid to be observed another bidder must bid a similar amount, or it must be "called," and this is unlikely. They define a three-stage game with "jump-call strategies" for the highest and the second highest value bidder. A "jump-call" strategy for the highest value bidder is driven by the desire to win the auction; for the second highest value bidder, the "jump-call" strategy is driven by the desire to make the highest bidder pay the high price. Gonzalez et al. develop a test for this class of equilibria by exploiting the sniping window. An auction with a successful "jump-call" bid should always terminate before the sniping window; if there is bidding in the sniping window then it must be because several people wanted to make jump bids. These auctions should be more competitive on average, and thus the average price should be higher. They find some evidence in favor of this hypothesis, but only 
if inexperienced bidders are included in the test. When auctions with inexperienced bidders are dropped, the null hypothesis of no jump bidding fails to be rejected at nominal significance levels.

Ely and Hossain (2009) emphasize a different purpose to such large early bids on eBay. In their model the amount of the bid is not critical. If an auction has a large early bid, then that would indicate there is real competition in the auction; thus it would be better to bid in a different auction. They call this type of bidding "squatting," which is essentially bidding to deter entry. Nekipelov (2007) finds a similar type of strategy in his model; and while he emphasizes the importance of entry deterrence in such a strategy, he refers to it as a "jump bid." Peters and Severinov (2006) have a similar result in that incremental bidding in their model enables optimal sorting, much like a squat bid in Ely and Hossain (2009) wherein if there is an active bidder in an auction, then one goes elsewhere.

\subsection{Estimation of Bidding Functions}

In our survey we have found that almost all empirical studies that use eBay data focus on bidder behavior, and thus we do also in this section. We will discuss the general literature here; a detailed discussion on methodology is provided in an Appendix to this paper: "Methodology: Structural Parametric and Nonparametric Methods in Online Auctions" by Seda Bülbül Toklu, which can be found at http://www.owlnet.rice.edu/ $\sim$ seda.bulbul/.

Substantial progress has been made in developing better methods to estimate bidders' behaviors in eBay single item auctions. The early papers essentially directly apply classic theory, while later studies also formally address entry. Only recently has research begun to deal with the thornier issue of exit. We are unaware of any paper that has successfully addressed both entry and exit in a cohesive structural empirical model.

Bidders who come to eBay generally bid on an item after some search and examination of the items. If outbid, the bidder can then repeat this process. It is possible that the bidder's past failure may influence future bidding behavior, based in part on the effort that he has expended in researching for the first bid that he has entered. The issues addressed by the various methodologies we consider below involve the size of the bid and what informs the bidder to select it.

Among the many possible considerations that are made by the bidders during the scenario we just outlined is that no consideration at all is given to the personal value that the bidder attaches to the item. Peters and Severinov (2006) examine a model in which the price is the value of the highest losing bidder in all of the auctions. Only one person, who will only bid in one auction, sets the price for every auction simultaneously. Of course this is only one of many possibilities, and there does not yet exist a general theory of bidding in eBay auctions and the empirical verification of this theory. This would be needed before we could characterize precisely how prices are determined in such an auction mechanism.

In the face of such uncertainty the appeal of reduced form or hedonic analyses is greatly enhanced. In such settings one can posit some causal relationship between 
the product's characteristics and the conditional mean of the sales price, and one can always appeal to arguments for local linearization of the bidding function. While the generality of one's conclusions with empirical models of this sort are not clear, one could argue that until there is a verified structural and general theory of bidding on eBay one cannot be any more confident of conclusions based on a general structural approach. Nevertheless, there has been at least one significant development in the literature that can be used to construct a joint model of the bidding function and the number of bidders; thus at the least one can estimate the entry function.

It has become clear that some variables such as feedback and the presence of a secret reserve price will have more of an impact on entry than on the bid given entry. For example, Dewally and Ederington (2004) are able to separate the number of bidders into an expected and unexpected number, and find that the two variables have significantly different impacts on the value of the wining bid. An increase in the unexpected number of bidders has about a $5 \%$ impact on the sales price, while an increase in the expected number has about a $1 \%$ impact. Livingston (2005) finds that the impact of the first few positive feedback reports is significant both in terms of entry and in terms of the price.

Sailer (2006) appears to have been the first, and to our knowledge, the only work that estimates a bidder's behavior taking into consideration the impact of exit. In the Sailer model it is assumed that all bidders enter the auction that will end first. They bid once, and after that particular auction has closed they move on to the next auction. When exit is possible bidders have to consider (when placing their bid) the continuation value that they will receive if they do not win a particular auction when placing their bid; and thus that value will be subtracted from their private value for the sale item. In the Sailer model, the continuation value varies across individuals since they have heterogeneous bidding costs. If one was to assume that all bidding costs are the same in the Sailer model, then the bidding costs would essentially be constant in the bidding function. This model is non-parametrically identified by applying the techniques of Song (2004) to identify the distribution of bidder's values, and then using this distribution to identify the distribution of bidding costs. Sailer finds that the average bidding cost is $2 \%$ of the final bid amount. Unfortunately, the technique in Song (2004) uses the third highest bid; and, unlike Song, Sailer does not carefully test which third highest bids can be safely utilized.

The Sailer model also can be simplified to make exit irrelevant, and implicitly this is the perspective taken in all studies that do not address exit. The term for this maintained position used in the literature is the steady state hypothesis. It posits that bidders are homogenous and the number of auctions, the number of bidders, and the characteristics of the auctions are all drawn from an identical distribution. Under this hypothesis the impact of exit will be absorbed in the constant term of a linear regression. One could weaken this assumption by merely assuming that all of these distributions are common knowledge. In this case the constant would be indexed by time. One could also consider that bidders do not have the same information about the continuation value, which would imply that the continuation value has a common value component. The importance of this component would depend on the extent of heterogeneity in the bidder's information set. This last complication may not have a significant impact, but it would be interesting to consider it formerly in future eBay auction models. 
None of the models we discuss below formally analyze exit. Instead they focus on the entry problem. Implicitly the authors assume that entry is not reversible, and thus that once the bidder enters the auction she can never enter a second one. If this is the case, then it should be clear that a bidder's strategy is not affected by the fact that she is in an auction marketplace once she has entered. Entry by itself causes few problems. It does put downward pressure on the reservation price, but does not affect the bidder's strategy.

Generally one assumes that bidders enter the auction without knowing their value for the good being auctioned, and that this entry decision follows a stochastic rule. In Bajari and Hortaçsu (2003a); Giray et al. (2010) and Nekipelov (2007) the random entry process is Poisson. Nekipelov (2007) adds the interesting twist that entry is endogenous - affected by the current price. This causes squat bidding, but otherwise does not affect the final amount bid.

With a stochastic entry rule one can use a number of estimation approaches, such as Bayesian methods (Bajari and Hortaçsu 2003a), maximum likelihood (Giray et al. 2010), simulated non-linear least squares (Gonzalez et al. 2009), and non-parametric methods (Song 2004; Adams 2007; Nekipelov 2007; Haker et al. 2010). Since we are analyzing English auctions, the difficulties of using maximum likelihood that Donald and Paarsch (1993) point out do not arise, and the Bayesian or maximum likelihood techniques are straightforward in theory, although this may not be the case in regard to their implementation. The non-parametric techniques are less familiar, and thus we will discuss them next in more depth.

Song (2004) was the first to provide a method to estimate the bidder's values nonparametrically. Given two bids one can identify the underlying distribution of values without identifying the number of bidders; and by using the third highest bid to identify the distribution as a function of the total number of bidders, one can substitute this out of the distribution of the second highest bid. Unfortunately, this leaves the analyst without information about the entry process, which is interesting in its own right. It also requires the use of some of the third highest bids. The use of such third highest bids can be problematic. While with the second highest bid the bidder knows that if he increases his bid, then he may win, and thus he should raise the bid to his true maximum willingness to pay, this logic does not hold with the third highest bid (or other bids), because after the bidder places his bid he may be outbid by two other people, resulting in a sales price above his true willingness to pay. Thus the bidder will not enter a new bid, the highest recorded bid will be less than the willingness to pay, and thus it would appear that we cannot use it with this nonparametric approach.

However, Song (2004) points out that the hard closing time of eBay auctions provides an out. Bidders who bid with only a few seconds left in the auction must know that the given bid is their last and thus should enter their true willingness to pay. Based on this insight, Song (2004) tests for which bids can be used in the estimates and finds that in general, as long as the first and second highest bid are submitted with two hours left or less, then the third highest bid can be used in the estimation. A final problem with this methodology is that much of the auction data are lost. The size of the data set is often much more important for nonparametric estimation than it is for parametric estimation. Since it is necessary to use only auctions where there have been three or more bidders in order to identify non-parametrically the distribution of bidders' 
private values, one must often also discard all auctions that did not attract that much competition.

In order to respond to these problems, Adams (2007) shows how non-parametrically to identify and estimate both the bidders' values and the entry process jointly. While this is a great stride forward, the assumptions that are required are quite stringent and would appear to be only tenable when analyzing relatively homogenous items. In the Adams model identification is achieved by having no common variables determine the entry process and the bidder's values. If the good is relatively homogenous, then this assumption may be defensible, since for a homogenous good entry will only be a function of the current price and the time left in the auction-neither of which should affect the bidder's value. However, even in this latter case, on eBay the seller's feedback rating will likely affect both the entry level and the bidders' valuations. Based on Cabral and Hortaçsu (2010), one may argue that the impact of the seller's feedback rating will be more important for the entry decision than the bidder's valuation and thus exclude it from the bidder's valuations, but this is just identification by an exclusion restriction, which presumably the champions of nonparametric identification would find problematic.

Nekipelov (2007) overcomes both of the problems in these methodologies. The main innovation in his model is that entry is endogenous. Potential bidders observe the price before they decide whether to enter or not. This innovation makes it possible to identify the entry function and the distribution of values non-parametrically. In Athey and Haile (2007) it is impossible to identify both the number of bidders (the entry process) and the distribution of bidders because the number of bidders is exogenous; thus an increase in the number of bidders or the distribution of values could both explain an increase in the sales price. On the other hand, with endogenous entry if the price increases due to an increase in the total number of bidders, another bidder is less likely to enter, while an increase in the distribution of values makes it more likely for a bidder to enter. Thus the two effects have a different impact on the entry process, making it possible to identify this process and then the distribution of bidders.

Nekipelov's methodology is computationally intense and implementation is difficult, but this is a hurdle that is worth the payoff. The model is a mixture of private and common values. While the value of the good itself is pure independent private values, the amount of entry is partially determined by a visibility parameter. Different bidders have different information about this parameter, and this causes a common value component to bidding. The auction is also modeled as a continuous time auction. Numerical techniques are used to solve for the equilibrium bidding strategies. Moreover, an innovative simulation methodology is put forth for estimation. The payoff from this complicated structural model is that it is identified non-parametrically under innocuous regularity conditions. Due to computational complexity, the key polynomial functions are only estimated as quadratics, and do not include standard control variables like the seller's feedback. Fortunately, the choice of data set makes this more innocuous than it usually would be, since the data set is made up of a relatively homogenous auction item, Madonna CD's. Since this is a relatively homogenous and low price good, trust would probably be inconsequential in such a market.

The Nekipelov study has both contributions to auction theory and to the econometrics of auctions. While it is cutting edge econometric methodology, theoretically 
it shows that the inclusion of a visibility parameter solves standard puzzles of bidder behavior on eBay. With this parameter and endogenous entry, bidders bid early (squat or jump bid) in order to deter entry; they bid at the last second (sniping) to prevent learning by their opponents; and they bid multiple times over the course of the auction. An implication of this theory is that if the supply of a good is exogenously increased, then there should be more squat bidding. This implication is tested in a field experiment by increasing the supply of the Robbie Williams CD "The Greatest Hits," and Hong and Nekipelov (2009) formally verify that there is more squat bidding.

If one is analyzing a common value auction, then the task of developing a model of entry becomes relatively more difficult. In such a common value auction Bajari and Hortaçsu (2003a) prove that bidders will only bid at the last minute. This transforms the problem formally into a sealed bid second-price auction, and makes the calculation of the bidding function relatively tractable. In order for this assumption to be strictly met, one would need all bidders to submit bids simultaneously, and this is contradicted by the data. However, there does not seem to be a tractable alternative at this time.

In the basic English auction model, once a bidder exits an auction he can not re-enter, and thus one can immediately back out the bidder's value based on when he dropped out of the auction. However, in eBay auctions bidders bid whenever and as many times as they want, and although it is clear that we can expect them to bid less than they may believe the item is worth, it is unclear how much lower we can expect them to bid. To understand this we would need to know why and by how much they will bid early; and as of yet we have no model that would provide such insight for common value goods. Thus bidders in an eBay auction cannot be sure if the bid that is observed for an opponent is the true final bid of these bidders or is a preliminary bid that will be updated at the last moment. In such an environment the direction suggested by the simplifying assumption of Bajari and Hortaçsu (2003a) is an expeditious way to proceed. While bidders may take into account the number of previous bidders in some reduced form manner, we think it is reasonable to doubt whether they can structurally estimate each bidder's value from his bid. This does not limit the analysts to only Bayesian estimation methodologies. They could equally easily use maximum likelihood, and in theory non-parametric techniques, although none of the non-parametric techniques discussed above were specifically designed for this purpose.

\subsection{Consumer Surplus}

One aspect of the eBay auction format and its ubiquitous presence that deserves more scrutiny is its ultimate benefit to society. It is relatively easy to develop an estimate of producer surplus (PS) based on eBay's gross merchandise sales. It is, however, possible to hypothesize that most values on eBay are drawn from a small family of distribution functions, in which case there should be some link between consumer surplus (CS) in different markets. For this reason it is worthwhile to estimate the CS in a variety of markets in order to gauge its range.

In order to assess the range of CS in different auction markets it is necessary to develop a standardized metric. There are two methods that have been suggested in the literature. Bapna et al. (2008) suggest using relative surplus while Giray et al. (2010) 
suggest using the lower bound of the consumer's share. For a given auction these two techniques are functionally related, but the former is more easily generalized while the latter is more stable.

Essentially, relative surplus is the amount of consumer surplus for each $\$ 1$ in sales. The attractiveness of this CS metric is its simplicity. Simply multiply relative surplus by the gross sales to arrive at the total consumer surplus in a given market. If $v$ is the consumer's value for the good and the price is $p$ then the relative surplus is $(v-p) / p=(v / p)-1$.

A problem with this technique is that if there is only one bidder in an auction, $p$ can be as low as one cent, or $v / p \in[1, \infty)$, making the relative surplus sensitive to outliers in low auction participation rates.

The consumer's share of surplus addresses the very important issue of the competitiveness of eBay auctions. As the number of bidders per auction grows, the consumer's share will tend to zero and vice-versa. If $r$ is the seller's value of the good, then the consumer's share is $(v-p) /(v-r)$. Unfortunately, estimating the seller's value of the good is difficult. Given eBay's fee structure, one cannot even assume that the reservation price always exceeds seller's value. However, one can assume that $r=0$, which simplifies the analysis substantially, and provide a lower bound on consumer share, $(v-p) / v=1-p / v$. This number is not easily and immediately generalizable but it is more stable than the relative surplus; it is bounded since $p / v \in(0,1]$, and thus it will be less sensitive to a thin market and a corresponding low number of bidders in a particular auction.

Bapna et al. (2008) offered eBay bidders the free use of a sniping program to collect their data. A bidder should enter his true value into the sniping program since the bid will be submitted at the last possible instant. This allowed the authors to collect a large number of data points in auctions where the winner's value is known with relative certainty. Unfortunately, their data set is also quite heterogeneous, and no attempt is made to control for this heterogeneity. Bapna et al. do compare their sampled auctions with a random sample of auctions and find no significant difference in characteristics between the two sets, which suggests that their sampled auctions are representative of the general population of auctions. This does not, however, address the potential problem that bidders using their program may not be a representative sample of potential bidders. Bapna et al. show that CS is very heterogeneous across different categories but only report the relative surplus over all markets. They find the median relative surplus to be 0.22 , corresponding to a lower bound on the consumer share of 0.18 . Based on their mean surplus per category they estimate that eBay generated $\$ 1.5$ billion of CS in 2003.

In her CS analyses, Song (2004) studies one very specific market: the market for university yearbooks. Using non-parametric techniques she estimates a median CS of $\$ 25.54$. Given a median sales price of $\$ 22.50$, this corresponds to a median relative surplus of 1.14 or a median lower bound of consumer's share of 0.53 . Given the relatively low amount of demand for these goods, it is not surprising that her estimate is so far above the general estimate of Bapna et al. (2008).

Giray et al. (2010) used a variety of parametric and Haker et al. (2010) uses nonparametric methods to estimate CS in the market for computer monitors. Using parametric techniques the median lower bound of the consumer's share varied from a 
minimum of 0.30 (based on logistic distributed private values) to a maximum of 0.56 (based on Pareto distributed private values). Giray et al. also utilized a number of nonparametric tests to search over the best parametric method. Their results favor logistically distributed private values, suggesting a preferred estimate of 0.30 for the lower bound of consumer's share. Hasker et al. utilized the technique of Song (2004) on a subset of the data and found that with either a full nonparametric or a semi-nonparametric method, the estimated lower bound on consumer share is around 0.22.

A problem with estimating CS using either nonparametric or parametric methods involves the sensitivity of estimates to the tail properties of the distribution of private values. Since nonparametric techniques assume that the density is zero when there are no nearby observations, this methodology will tend to underestimate CS. The differences between the nonparametric and the parametric estimates from Giray et al. are consistent with this potential downward bias. On the other hand, the tail properties with parametric techniques are often determined by observations that are far from the tail, since the support of the one-sided private value distributions is typically unbounded.

\section{Seller Decisions and Reliability}

The sellers' various decisions are not as well understood as the buyers' decisions. The seller has a much more complex problem, one for which the complexity has greatly expanded lately, and it is thus natural that our understanding of it is not as clear. This section begins by looking at the most important and yet least understood choices involving the selling format. There are a large number of selling formats available on eBay and practically every one is used in every category, even for the same item. We briefly review the literature on this topic, a literature that is clearly in need of more significant development. We then focus on the three primary decisions that a potential seller using an English auction has to make. These involve setting the public reservation price ("first bid"), setting the secret reservation price (or simply "reservation price"), and the decision to use a Buy it Now (BiN) price. We end the section with a discussion of reliability and trust in eBay auctions. We focus on evaluating evidence on outright fraud and other dishonest behaviors on eBay and the effectiveness of the feedback system that successfully reinforces the seller's honesty.

\subsection{Selling Format}

The choice of selling format is an under-researched topic in the eBay auction literature. eBay has recently started allowing all sellers to sell by Auction, Fixed Price, and Bargaining, but there has been little analytic work addressing these decisions and their impacts on the auction mechanism. Table 1 provides evidence of the mix of selling formats on eBay. Overall, $73 \%$ of items are sold by fixed price (BiN), $14 \%$ by bargaining ( $\mathrm{BiN} \mathrm{oBO}$ ), and $12 \%$ by auctions. The ratio of listings between auctions 
and the other categories requires a bit more explanation. All store inventory (69\% of listings) is listed as $\mathrm{BiN}$ or $\mathrm{BiN}$ oBO and is listed until cancelled. ${ }^{14}$

The variation among categories is substantial. $71 \%$ of all Real Estate is listed as auctions, Specialty Services is $94 \%$ fixed price, and Tickets is $39 \%$ bargaining. With the exceptions of Specialty Services, Real Estate and Stamps, no major selling technique is represented by less than $5 \%$ of the listings in any category. For specific items the diversity is similar. Of the 2,438 January 2009 listings of the Nintendo Wii Game console system in new condition, $49 \%$ were for a fixed price, $24 \%$ allowed bargaining, and $27 \%$ were auction listings. For a new copy of the Dark Knight DVD there were 260 listings of which $61 \%$ were for a fixed price, $8 \%$ were available by bargaining, and $31 \%$ were being offered in auctions.

Much of the first generation theory on seller behavior focused on explaining when one type of selling mechanism or another was superior. For example, McAfee (1993) showed that competing sellers will choose an auction, even if they choose among all the mechanisms on eBay. Riley and Zeckhauser (1983) show that if buyers arrive one at a time, then a fixed price mechanism is always the best type. However, heterogeneity in sellers on eBay is no less important and is often-overlooked factor as with buyers. Harris and Raviv (1981) show that a monopolist seller with large capacity will use a fixed-price format, while a seller with small capacity will use the auction format. Although instructive, this prediction from their model is at variance with the observation that many eBay virtual stores use both auctions and fixed-price selling. Circumstantial evidence suggests that some of these auctions are for advertisement but a casual survey suggests that stores often are auctioning too many items for this purpose alone. $^{15}$

There are several studies that have tried to explain at least two of the seller mechanisms. Most of these explicitly require the seller to be a monopolist. Bose and Daripa (2009) solve for the optimal mechanism when there is a significant probability that a bidder may have a fixed high value. They show that this implies a fixed price for the high value bidders but that the mechanism can be decentralized using a fixed-price sale and an auction with a temporary BiN option. However, the reason the high value consumers buy at the fixed price is because if they do not, it might be purchased by another high value bidder at the fixed price. On eBay there are auctions and fixed price sales running simultaneously, and it is unclear if the Bose and Daripa findings are applicable to the reality of the eBay marketplace. In Etzion et al. (2006) buyers can always choose to bid in an auction or buy at a fixed price. They enter the auction because they are impatient. Unfortunately, eBay auctions are closing continuously, which implies that no one should buy at a fixed price.

Several papers have shown that if either bidders or sellers are risk averse, then auctions with a permanent BiN option are revenue superior to an auction alone (Hidvégi et al. 2006; Mathews and Katzman 2006; and Reynolds and Wooders 2009). It may be possible to extend these models and show that a seller would do better to use both fixed price and auction sales. Kultti (1999) takes a different approach by explicitly

\footnotetext{
14 The sellers can list the items for 30 days, but the listing is automatically renewed. Auctions can last a maximum of 10 days.

15 See http://www.nytimes.com/2004/12/07/business/businessspecial/07GUER.html.
} 
analyzing a market where sellers can either use a fixed price or auction and where there are new sellers entering each period. He shows that in the dynamic equilibrium the choice of mechanism may not matter, since both produce the same average revenue.

While the standard eBay auction and the auction with a BiN price are widely used, the fixed price selling format with a "Best Offer" option is used rarely. The seller is allowed to use the "Best Offer" option in the fixed price (BiN) and classified ad selling formats. With this option, the seller gives the buyers a chance to negotiate the price with him; hence we call it the "bargaining selling format". After the seller receives a Best Offer from a buyer, he can either accept it and end the listing, decline it and optionally explain the reason to the buyer, or respond with a counter offer that expires within a reasonable amount of time if there is no response from the buyer.

The evaluation of the Best Offer from a buyer can be done individually or automatically. For automatic evaluation, the seller sets a lower limit below which the Best Offers are automatically rejected, and an upper limit at or above which the first received Best Offer is automatically accepted. The seller responds individually to Best Offers between the upper and the lower limits. For all the rejected Best Offers, the seller has the option to respond with a counter offer below the BiN price.

There has been relatively less analysis of bargaining versus either of the other seller methods, and perhaps this is natural since it is well known that bargaining with incomplete information can be inefficient. The common belief that auctions are most often used as opposed to posted price when the object value is widely dispersed among buyers is confirmed by the findings of Wang (1993) in a dynamic independent privatevalues model. However, Bremzen (2004) shows that a posted price can be a costly signal of high quality, and one can conjecture that this would explain the use of posted prices as well as auctions or bargaining. While this is intuitively worthwhile it seems to contradict the evidence that items sold in new condition are commonly bargained and auctioned.

A general insight offered by Levin and Smith (1994) may be relevant in this context. They find, when considering only auction mechanisms, that a more general revenue equivalence theorem holds because mechanisms that offer more surplus attract more entrants. Thus on average, all of the mechanisms may offer a similar surplus. In other words, any two auctions that are revenue equivalent for a fixed number of bidders remain revenue equivalent in a mixed-strategy entry equilibrium. Remembering the result of Reynolds and Wooders (2009) that when a buy price is low enough to be accepted with positive probability, then the BiN auction yields less revenue than a standard eBay auction for risk neutral bidders, we can say that Levin and Smith's generalization would not seem to explain the coexistence of buy prices and standard auctions.

There is ample evidence that some sellers have long sought the fixed-price sales format. eBay has allowed store owners to use this technique since 2003, but has only recently allowed other sellers to use this format. Before this recent inclusive change, many sellers were able to enter an auction with a BiN option and set the first bid so high that bidders could essentially only buy at the fixed price. Anderson et al. (2004) noted that $40 \%$ of the auctions in their study with a BiN option were actually using this way to sell at a fixed price. Of the 133 auctions that were not fixed-price sales, only one ended at the BiN price. They analyzed auctions for Palm Vx handheld com- 
puters and found that more experienced sellers were more likely to use fixed-price selling, although this was less likely to happen if the item was new. Hendricks et al. (2005) found the same tendency but it was even more widespread in the market for TI calculators. Out of the 3,000 transactions approximately 30\% used a temporary BiN and for the substantial majority of these the first bid was at least $90 \%$ of the BiN price.

Understanding the advantages of this popular alternative and the potential for this type of selling format displacing the typical eBay auctions format is a research topic that deserves attention. Any theory that attempts to understand these phenomena should pay careful attention to Standifird et al. (2004) and Lee and Malmendier (2007). Standifird et al. (2004) auctioned 84 American Eagle silver dollars and found that bidders were reluctant to buy at the BiN price, even when it was substantially below the market price. Even more problematic are the findings of Lee and Malmendier (2007) who study the market for the board game Cashflow 101 with a retail price of $\$ 195$. While it was a relatively thin market, with less than 50 auctions per month, there were two professional sellers who consistently sold the game using a fixed price. The average sales price in the auctions was higher than the average fixed price. Seventy-four percent of the auctions ended at a price that was above the fixed price, while $25 \%$ ended ten dollars or more higher. As Ariely and Simonson (2003) point out, it would seem that consumers under-search, and this could lead to consumers over-paying, a conjecture that is supported by the eBay search engine itself. The eBay search engine allows one to select items being auctioned and items being sold at a fixed price, and thus buyers who like one format may not check other options.

\subsection{Choices in an English Auction: Buy it Now, Reservation Price, and the Secret Reservation Price}

A seller has four variables that he can choose when he uses eBay to auction his goods: the length of the auction, the first bid (public reservation price), the reservation price (secret reservation price), and whether to offer a BiN option. We discuss each in turn, focusing more attention on the latter three variables in subsequent sections.

eBay auctions currently run for $1,3,5,7$, or 10 days. ${ }^{16}$ Only recently has eBay allowed auctions to have a shorter duration, and we are unaware of any formal analysis of this decision using recent data. Two papers analyzing the choice of length of auction using data from the early days of eBay are Gonzalez et al. (2009) and LuckingReiley et al. (2007). Lucking-Reiley et al. (2007) analyze the market for collectible pennies by using reduced form log-linear regressions of price on the number of days. They find that extending an auction from 3 to 10 days increases the sales price by $53 \%$. Gonzalez et al. (2009) analyze the market for computer monitors with a structural model, wherein the number of potential bidders was determined by the length of the auction. They found that increasing the auction from 3 to 10 days increased the price by only $11 \%$ on average, and $8 \%$ of increase could be captured by extending the auction from 3 to 5 days. They also found that more experienced sellers tend to use shorter auctions for low-price goods.

$\overline{16}$ In Real Estate, auctions can run for 30 days. 
Whether or not these results would hold for more recent auctions is an interesting research question. We do know that eBay has decided to allow shorter auctions, which would indicate some demand for them. The conditions under which auctions of varying durations would be optimal is also an understudied topic that would be the basis for a potentially fruitful research agenda.

\subsubsection{Reservation Price}

There are two outstanding puzzles concerning reservation prices. The first involves the seller's common preference for a secret reservation price (which is called a "reservation price") over a public reservation price (which is called a "first bid"), even though there is an additional fee for using a secret reserve. ${ }^{17}$ The second involves the reasons why (in general) reservation prices are set so relatively low. In the traditional auction literature Myerson (1981) and Riley and Samuelson (1981) showed that the seller can significantly increase his revenue with an appropriately chosen reservation price. For a private values good the main benefit is screening since if there is only one bidder in the auction, the reservation price is the amount the bidder must pay. If there are affiliated values, then Milgrom and Weber (1982) emphasize a secondary benefit of a reservation price, since the fact that the seller thinks that the item is valuable may raise the bidders' assessment of the item's value. Samuelson (1985), in a procurement auction setting, finds that the buyer minimizes his expected procurement cost by setting the ceiling price strictly below his cost, while the social cost is minimized by setting the two values equal. On the other hand, other papers conclude that when an auction has entry, the reservation price should be set at the seller's (or, in a procurement auction, buyer's) valuation (Engelbrecht-Wiggans 1987; McAfee and McMillan 1988; Levin and Smith 1994).

In the Gonzalez et al. (2009) study of computer monitors this would suggest that $12 \%$ of the sellers must value the monitors at less than one dollar, which does not seem likely. Furthermore, field experiments find that increasing the reservation price does increase the selling price. Häubl and Popkowski Leszczyc (2003) auctioned identical postage stamps while systematically varying both the first bid and the shipping and handling fees. They find that increasing either variable did increase final sales price significantly. Ariely and Simonson (2003) studied tickets for the Rose Bowl and found that the first bid (public reservation price) was positively correlated with the price.

Market saturation may be one factor in the disparate findings of how price and reservation price are related. Ariely and Simonson (2003) show that if many similar items are auctioned simultaneously, then the first bid has little impact on the sales price. Hoppe and Sadrieh (2006) compared auctions with the first bid set at the minimum or $60 \%$ of the blockbuster movie DVDs and collectible coins value. The sales price was basically independent of the policy, and thus auctions with a low first bid produced higher profits because of lower fees. Since the only case in which the first bid matters in the classic theory of Myerson (1981) is when there is one bidder whose

17 Currently this is the higher of $\$ 2$ or $1 \%$ of the secret reservation price, with a maximum of $\$ 50$. 
value exceeds the first bid in the auction, then if the probability of this is low enough, small first bid fees could induce auctioneers to have very low first bids.

Another explanation may come from the fact that eBay itself does not charge for shipping and handling fees. Häubl and Popkowski Leszczyc (2003) show that raising the shipping and handling fees can increase the revenue. Hossain and Morgan (2006) auctioned Xbox games, and found that low first bids and high shipping costs raised more revenue than high first bids and low shipping costs, although they did not find this to occur with music CD's where shipping fees are often a large percentage of the sales price. This may be one reason that eBay now automatically computes the shipping and handling fees. eBay even allows users to sort based on the price plus the shipping and handling fee. It is unlikely that the modern eBay bidder will ignore these fees.

\subsubsection{Secret Reservation Price}

The economics literature is often silent on the subject of secret reservation prices and may give the impression that usually reservation prices are public knowledge in auctions. This is in keeping with the ground breaking works of Riley and Samuelson (1981) and Milgrom and Weber (1982), who argue convincingly against keeping this information secret. However, Ashenfelter (1989) points out that in reality there is often a secret reservation price in auctions. One can readily confirm this by checking the Sotheby's website, where the term "secret" reservation price is not used. The term "reservation price" is generally understood to be for a price that is confidential between the seller and the auctioneer. The fact that this common empirical behavior is not addressed in most auction models is somewhat problematic.

eBay may well be an excellent platform for understanding this phenomenon. There is theoretical support for the usefulness of a secret reservation price in the private values environment. Brisset and Naegelen (2006) show that if bidders are risk averse and the seller can commit to using a secret reservation price, then it may be an optimal seller strategy. For a secret reservation price to be optimal the seller must be unsure about the value of the good for her when she decides to sell it (i.e., the seller is uninformed).

If the auction is not pure private values, then the use of a secret reservation price is less theoretically questionable. Hossain (2008) develops a clever alternative explanation for the optimality of a secret reservation price. If a bidder can only assess his willingness to pay the current price for an item, then a secret reservation price would encourage the bidder to continue bidding in order to acquire more information. Furthermore, with affiliated values a high public reservation price may discourage entry, and the signal sent by having a large number of people enter the auction may outweigh the signal sent by the auctioneer's reservation price. For example, Vincent (1995) provides an example in which a secret reservation price can increase revenue in English auctions. Rosenkranz and Schmitz (2007) show that when the reservation price enters the bidder's utility function as a reference point and when the optimal reservation price is lower than the price that is attainable from an outside offer, then the use of a secret reservation price is an optimal seller strategy. This insight may hold more generally, if the signal sent by the outside offer is diminished by the signal contained in the reservation price. However, this conjecture has not been formally modeled. Horstmann 
and Lacasse (1997) show that if the seller can open a second subsequent auction, then a secret reserve price may be optimal; but this requires that the bidders know the seller is reselling the good and it is unclear if this would be realistic given the eBay auction formats.

Following the work of Vincent (1995); Bajari and Hortaçsu (2003a) find an optimal selection criteria for the secret reservation value that increases seller revenue. The increase is, however, quite minimal (at about 1\%) and the results are highly leveraged by their structural model. In part because of this, Katkar and Reiley (2006) conducted a field experiment selling Pokemon cards on the Internet and found that a secret reservation price brought $10 \%$ less revenue on average. They also found that the presence of a secret reservation price reduced the likelihood of an auction's ending in a sale by about 30\%, although the number of bids did increase, in keeping with Vincent (1995). Unfortunately, any definitive conclusion based on the Katkar and Reiley study is hampered by the size of the data set. Were the sample larger, it may be possible to estimate the relationship between revenue and the reserve price and then compare, like Bajari and Hortaçsu (2003a), the optimal values for both the public and secret reservation price. The relationship between the existence of a secret reservation price and the number of bidders found in Katkar and Reiley (2006) was not found by Dewally and Ederington (2004) who studied the market for silver age comic books. The presence of a secret reservation price decreased the number of active bidders by about 1.5 , but it has an insignificant impact on the sales price.

This long-standing puzzle in auction theory has not been resolved and with the potential size of eBay data sets based on data mining algorithms, the potential exists for very large scale empirical studies of such issues to be carried out. It is an excellent environment to study and understand the rationale for using a secret reservation price.

\subsubsection{Buy it Now}

A unique option in eBay auctions is the Buy it Now (BiN) price. Generally on eBay this option disappears as soon as someone bids more than the secret (or public) reserve. ${ }^{18}$ There are several explanations for why a seller would want to use a BiN price. These explanations usually rest on several factors, including impatience, risk aversion, and the distribution of format types.

Reynolds and Wooders (2009) show that when the seller is risk neutral and the bidders are risk averse, both "temporary" (eBay style) and "permanent" (Yahoo! style) BiN prices raise more revenue than does the ascending bid auction for a wide range of buy prices. Moreover, for a given buy price, the permanent type raises more revenue than does the temporary type.

Another paper considering both temporary and permanent BiN prices is Gallien and Gupta (2007). They explain the use of both types of BiN prices by impatience, which makes their work closely related to the work of Mathews (2004). In their model the seller and the bidders are risk-neutral and impatient, and there is entry according to a Poisson process. In contrast to Reynolds and Wooders (2009), they do not consider

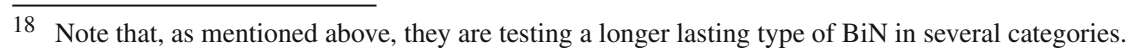


reserve prices. Using numerical simulations, they find that a temporary BiN price gives a higher expected utility to the seller. They also find the optimal BiN price when there is no reserve price. It is important to note that in their simulations the seller cannot vary either the reserve price or the duration of the auction, the latter of which would seem to be especially important given the impatience of the sellers.

The compelling argument of risk aversion is also used by Mathews and Katzman (2006). They consider the joint choice by the seller of the temporary BiN price and the reserve price in a model with risk averse sellers and risk neutral bidders. They show that the seller maximizes his expected utility with a BiN price low enough that it is accepted with positive probability and with a reserve price lower than what would be optimal if no BiN price were possible.

As mentioned above, Bose and Daripa (2009) derive the optimal mechanism and show that implementing this mechanism requires the use of auctions with a temporary BiN price. In their model, a risk neutral seller first offers the item for sale at a posted price to risk neutral bidders. If it fails to sell, then he offers it for sale at cost $c>0$, via an auction with a temporary $\mathrm{BiN}$ price. However, their assumption of the degenerate distribution for the high valued buyers' value constitutes a less compelling base for explaining the use of $\mathrm{BiN}$ prices than the assumptions of risk aversion or impatience on the part of bidders.

Shahriar (2008), differently from the papers mentioned thus far in this section, assumes common value and shows that a temporary BiN price does not raise seller's revenue with either risk-neutral or constant-absolute-risk-averse bidders. Shahriar and Wooders (2007) is an experimental study that considers both private and common values. Their finding that a temporary BiN price raises seller revenue when values are private, supports risk aversion on the side of bidders as an explanation for the use of BiN prices.

eBay states that it uses the temporary BiN out of a sense of fairness, thinking that bidders would complain if, after seeing that they were winning an auction, the item was bought at the BiN price. eBay goes on to say that there is evidence that a longerlasting $\mathrm{BiN}$ option might bring higher revenue to the seller and uses this to justify its current experiment where the $\mathrm{BiN}$ price is available until $50 \%$ of the $\mathrm{BiN}$ price has been met. ${ }^{19}$ Lastly, it is important to be aware that all of the models that are considered in this section (like the vast majority of the literature on auctions) are based on a single auction, and hence do not fully capture the complexity of eBay where, often, there are many auctions of similar items taking place at the same time.

\subsection{Trust, Feedback, and Corruption in eBay Auctions}

One of the biggest problems that eBay auctions face is asymmetric information. In any used good market this is a problem. On eBay one cannot even inspect the good before bidding on it. The problem with asymmetric information is exacerbated by the

19 Seehttp://forums.ebay.com/thread.jspa?threadID=2000449591\&rw=true \&anticache=1234510256015. 
sheer scale of business that is conducted on eBay. In 2007 a common problem was the hijacking of the identity of established sellers in order to market spurious items. ${ }^{20}$

Jin and Kato (2007) examine how buyers and sellers of sports cards have adapted to deal with the tradeoff between search cost savings advantage and information asymmetries disadvantage of online markets, and how this has affected traditional retail markets. They show that in equilibrium, the overall market is split into offline and online segments depending on the quality of the cards and their certifications, which is also supported empirically. Their data also suggest the shrinkage of the traditional retail market after the arrival of the online marketplace.

Kazumori and McMillan (2005) suggest that depressed prices due to asymmetric information problems might have been part of the reason that Sotheby's stopped selling art on the Internet. Furthermore, Riefa (2008), offering a UK and EU perspective, points to the lack of legal protection for buyers on eBay. eBay does not qualify as an auctioneer, and the EU's Electronic Commerce Regulations of 2002 have a lenient legal framework. Moreover, there is no legal protection for consumer-to-consumer auctions.

eBay has put in place a number of safeguards to deal with these issues. It originally instituted its feedback system to help counteract the problem. It purchased PayPal, an online payment system, and it now actively encourages buyers and sellers to use PayPal. PayPal provides insurance for a buyer up to $\$ 20,000$; and if the item is not delivered or is not as described, then payment is not made to the seller. eBay has also begun to report the percentage of negative feedbacks on the listing page, which provides bidders with more transparent information about sellers with bad reputations. Cabral and Hortaçsu (2010) found this change in reporting sellers' reputations to have increased the impact of a negative feedback on price. eBay's detailed service report for sellers now rates the seller in five different categories. eBay now distinguishes between reputations that are based on sales and reputations that are based on purchases, and no longer allows sellers to give buyers a negative feedback rating. eBay also has provided a voluntary ID verify service that authenticates the identification of buyers and sellers. eBay requires this ID verification for items priced over $\$ 15,000$.

This section will analyze this serious issue for eBay. First we will discuss the amount and cost of fraud on eBay. We next discuss a specific type of fraud: shill bidding. We end the section with a discussion of the estimated impact of negative feedback on an eBay seller.

\subsubsection{The Amount and Cost of Fraud on eBay}

Jin and Kato (2006) directly estimated the amount of fraud-or misrepresentation of a good's value-in the market for baseball cards. There are professional grading services for baseball cards, but some sellers do not use these services and instead simply offer their opinion on the quality of the baseball card. Jin and Kato bought the ungraded cards and then submitted them to a grader to estimate whether the claims of the owners were fraudulent. They found that sellers who claimed that their card

20 See http://www.ecommerce-guide.com/essentials/ebay/article.php/3652611; http://www.theregister. co.uk/2007/03/21/ebay_fraud_anatomy/. 
was either "mint" or "gem mint" received a $27 \%$ higher price, but these sellers had relatively lower average ratings than did the sellers of ungraded cards. Since the prices that were paid for ungraded cards were substantially below the price for graded cards, it would appear that the seller's claims were discounted by the buyers, but perhaps not discounted enough.

The cost of fraud on eBay can also be assessed by comparing the prices on eBay to those received elsewhere. The problem with this comparison is that auctions on eBay probably face greater competition, and as Sailer (2006) shows, the exit value of a bidder on eBay should decrease the amount that he is willing to bid. A structural model could be developed that would estimate both the exit value and the number of bidders per auction. The two papers of which we are aware that have estimated such a model have only estimated only the impact of various factors on the price. Dewan and Hsu (2004) compare prices from eBay to prices of identical items from an established stamp seller. They find that eBay prices were 10-15\% less, with the differential increasing as the stamp became more expensive. However, eBay has approximately 100,000 stamp auctions going on at any one time, while the established stamp seller (Michael Rogers) runs auctions only twice a year. Furthermore, the Dewan and Hsu study analyzed stamps that were Michael Roger's specialty, stamps from East Asia.

Their results, however, were supported by Diekmann et al. (2008), who analyzed tractor auctions on eBay and live auctions and found the predicted price on eBay was, for the median tractor, $31 \%$ lower than the predicted price in a live auction. However, if they restrict their estimates to items that cost less than $\$ 20,000$ (and thus are covered by PayPal insurance), the eBay discount drops to $26 \%$. Moreover, some tractors were sold for higher average prices on eBay. An interesting side issue is that their results suggest that it is more profitable to sell a tractor for less than $\$ 20,000$ on eBay. They are able to report fees only for a competing online auction website, but the fixed fee charged at that site, which almost covered the median price difference, and the $12 \%$ commission (compared to about $2 \%$ on eBay) would make it much less profitable. There may be an asymmetric information hazard on eBay, but at least in this particular example it appears to be the best place for the seller.

\subsubsection{Shill Bidding}

One particularly pernicious form of abuse in eBay auctions is shill bidding. Essentially, the auctioneer submits bids using a different identity to drive up the price. This allows the seller to set a secret reserve price without paying the associated fee, though in general there is some risk that he will end up purchasing the item. Several authors (Chakraborty and Kosmopoulou 2004; Sinha and Greenleaf 2000) have shown that if the seller could commit to not use shill bidding he should, but there is no credible way to enforce this commitment. Thus we would expect to see quite a bit of shilling on eBay, and unfortunately this is the hardest type of corruption to detect. Whether or not it is common on eBay is an open question.

Engelberg and Williams (2009) point out that the way that price is determined on eBay actually makes it possible to shill-bid without risk. The transaction price on eBay is the second highest bid plus a bidding increment or the bid of the highest bidder, whichever is lower. This means that if a shill bidder can bid within a bidding increment 
of the highest bid, then she can discover the high bidder's value, since it will be the sales price. Combined with anecdotal evidence that bidders almost always state values ending in a dollar or fifty cents, a shill bidder has a perfect strategy: merely make sure that every shill bid ends in an odd number of cents (X.37, or $X .29$, etc.) and always increase your bid by less than the bidding increment. After enough bids the seller will reach the high bidder's bid with certainty. However, Engelberg and Williams (2009) examined auctions for 40,000 event tickets and found that only $3 \%$ of all bids seemed to use this strategy, while only $1.5 \%$ of all bids were actual shill bids.

A problem with the sustainability of the shill bidding strategy is that sniping may make it ineffective. The hard closing time works to the advantage of eBay by decreasing the gains from this type of fraud. When bidders snipe, the seller has no time to drive up the price. Still, questions arise about the benefits of shill bidding. Hoppe and Sadrieh (2006) sold DVDs and collectible coin bundles using three different techniques: a low first bid alone, a low first bid and a secret reserve set at $60 \%$ of the book value, and a low first bid with a later shill bid of about $60 \%$ of the book value. They found that the revenue was basically indistinguishable among the three methods.

\subsubsection{The Effectiveness of Feedback: Adverse Selection or Moral Hazard?}

There are several analyses with different conclusions about the effect of seller's feedback on price depending on the methodologies that are applied, the variables that are controlled for, and how expensive the item under examination is. The methodologies that are used to examine this effect would appear to be better suited to testing for adverse selection. However, if it is not adverse selection but rather moral hazard that is the key problem, then the methodologies used to estimate this relationship may be flawed. Studies that test for moral hazard typically find large and significant effects though they do not estimate the total cost of negative feedback. This is one of the fundamental issues that must be understood in order to assess the viability of the eBay marketplace.

If the effectiveness of feedback is driven by adverse selection, then there are different types of sellers, some good and some bad. In this case, a seller's feedback score plays the role of a signal that reveals information about the reliability of the seller and hence decreases the information asymmetry that distorts the auction mechanism. This eventually increases the sales price of the good, which would have been low due to the low expectations of the under-informed bidders. The best way to tell the type of a given seller is to take a large sample and look for the number of positive responses. This is essentially what feedback or even better, what the percentage of positive feedbacks represents. The early papers investigating this effect were Lucking-Reiley et al. 2007 and Houser and Wooders (2006). Houser and Wooders (2006) find, in a study of Pentium processor auctions, that an increase in a seller's feedback from 0 to 15 positives would increase the final sales price by about $5 \%$, which is an economically significant amount. On the other hand, Lucking-Reiley et al. (2007), in a study that can be found to be weak for not controlling for the variation in market value of coins in the auctions they study, do not find positive feedback to be statistically significant.

If a researcher wishes to test for whether or not there is a large adverse selection problem on eBay, then he would typically regress price on total feedback or total 
negative feedback as well as other auction specific controls. A number of studies have used this approach and have found little explanatory power for the various measures of a seller's reputation. This general evidence is summarized in Resnick et al. (2006), who report that the impact of one negative feedback is trivial. To estimate the impact of feedback alone, controlling for items auctioned, wording, and other aspects, Resnick et al. conducted a field experiment wherein inexperienced and experienced sellers $(2,000+$ feedback rating) sell the same items. They found an $8.1 \%$ premium for having a high reputation.

One problem with these studies is that they look only at relatively low cost items: typically auctions in which there is little chance that the bidder loses much money. Andrews and Benzing (2007), however, looked at the market for used cars-specifically, Honda Accords. In this market not only is there a known asymmetric information problem, but the average price was $\$ 6,437$. They found that there was a premium for professional dealers and cars with clear titles, but also found that a good reputation did not increase the sales price. They did find that the probability of sale was affected by reputation, in keeping with other studies.

Adverse selection was also studied by Livingston (2005), who examined the impact of the first few positive feedbacks on price and found evidence of an adverse selection problem on eBay. A theoretical implication of the model developed by Livingston is that the first few feedbacks are much more important in determining a seller's reputation than are other subsequent feedbacks, and this is borne out empirically. The Livingston study also points out that many other papers that study the adverse selection problem utilize rather restrictive structural models. This limits the role that seller feedback can have in determining price and thus (with standard estimation methods) in revealing a significant empirical link between total feedback (or total negative feedback) and price.

While feedback can help an honest seller develop a reputation in a way to decrease the information asymmetry, it is true that a seller, who will not sell on eBay anymore, can find it optimal to use his reputation to cheat in his last transactions and earn a high profit just before leaving. If instead of adverse selection distorting the auction mechanism, the real culprit is this problem of moral hazard, then the total number of positive feedbacks is not a relevant indicator of reputation, and what should matter most to the bidder is the recent behavior of the seller. This suggests that, independent of history, if one gets a negative feedback there should be a reaction, and one's recent feedback should matter much more than one's total feedback. Cabral and Hortaçsu (2010) find empirical support for this in that a seller's first negative feedback is significant in the final price, but there is less of an impact from further negative feedback ratings. They show that when a seller receives his first negative rating, his weekly sales rate drops $13 \%$, and that even though the second negative arrives about $25 \%$ faster, it has relatively little impact.

In their study Cabral and Hortaçsu (2010) collected the data in a way that the probability of a seller receiving feedback is uncorrelated with the probability of receiving a negative (positive) feedback (i.e. no selection). In order to support their assumption, they carry out a statistical analysis of this potential selectivity problem and find that the probability of feedback is uncorrelated with a variety of seller characteristics. However, a buyer who observes a negative seller feedback rating may have a higher 
threshold for leaving a positive feedback, and thus it is still possible that the percentage of positive feedbacks could decrease after one negative feedback. Since they base their analysis solely on the feedback histories, this could appear as a drop in the number of sales.

Results of Cabral and Hortaçsu (2010) were confirmed by Eaton (2007) who estimated the probability of sale in a market for electric guitars based on recent feedback. If total negative feedback is used to measure the seller's reputation, then the impact on price is trivial; if negative feedback in the last 6 months is used, then the elasticity is -.15 , while if negative feedback in the last month is used, then he finds that an additional negative rating will decrease the probability of sale by $9 \%$. Eaton also finds similar results for positive feedback and, interestingly, that the type of feedback is also important. Negative seller feedback strongly decreased the probability of a sale while negative feedback about the product itself (perversely) increased the probability of a sale.

It is somewhat surprising that after so many years of analysis, the efficacy of eBay's feedback mechanism is so poorly understood. The available evidence would suggest little adverse selection on eBay. However, there is only limited evidence about the effectiveness of the feedback mechanism in the face of a moral hazard problem. Both Cabral and Hortaçsu (2010) and Eaton (2007) estimate the impact on the probability of a sale and not the sales price. It is unknown what the cost is to a representative seller. These appear to be open issues that are ripe for research that would be of great interest to an eBay bidder and to eBay itself.

One last point involves what methods could be utilized in order to establish trust. Dewally and Ederington (2002) analyze the market for silver age comic books and find that the professional certification of a comic book is worth more than a high reputation of the seller. They estimate that about $58 \%$ of the comic books should have been certified while only $29 \%$ actually were. Certification was the only method of conveying quality which had a significant impact. Warranties and the provision of additional item information had little impact on sales price. Standifird and Weinstein (2007) conducted a similar study with Morgan Silver Dollars. In this industry there are many different accreditation firms. The authors found that using one of the accreditation firms with a good reputation had a significant positive impact on the price, but that using one of the accreditation firms with a bad reputation hurt the final sales price. Perhaps this is an avenue for eBay to explore in order to address the asymmetric information problem. eBay could easily provide links to established accreditation firms and make it clear how much of a benefit this could be to the sellers in extracting the best price for their items.

\section{Conclusion}

eBay is now the strongest online auction marketplace in the United States, with gross merchandise sales that make it equivalent in volume to the sixth largest traditional retailer. However, it is not a traditional retailer; instead it is a forum used by other people to buy and sell their goods. This makes it a market where many small and independent decision makers decide on how the market behaves. Indeed it is nearly 
the fabled centralized marketplace that is assumed in neoclassical competition theory. For this reason as well as for the prevalence of auctions on the eBay platform, it is of great interest to economics.

Indeed eBay's recent push towards increasing the amount of fixed price selling will allow us to see empirically whether the auction mechanism can compete with more traditional selling techniques. Several eBay commentators have stated that they believe that auctions - the source of 58\% of eBay's gross sales in 2008 - are on their way out, dying due to the convenience of fixed price selling. The authors believe that these pundits underestimate the attractive properties of auctions, but who is right will be revealed with time.

This, of course, brings us to one of the primary puzzles that is still only partially understood about eBay. Nowadays sellers use fixed price sales (Buy it Now), bargaining (Buy it Now or Best Offer) and auctions. Why do they use so many different techniques? Often the same seller will use all of the different techniques and one can easily verify that popular items are being sold by all of these techniques. Is the explanation based on the risk aversion of the bidders? If so, why do they use bargaining, which has been usually believed to be inferior to one of the other techniques? Or- to put the shoe on the other foot-since bargaining on eBay always allows for sales at a fixed price, why is it not always revenue superior to use this type of bargaining? And at the same time, does the choice of mechanism matter? Does some sort of general revenue equivalence hold on eBay with formats that promise more surplus resulting in more entry? These are just some of the mysteries of seller behavior that need to be better understood. Perhaps the other single greatest remaining mystery is why so many sellers use secret reservation prices. This and the low public reservation prices in many auctions should be studied further.

Buyer behavior, as mentioned above, is generally better understood. We still do not have a convincing general theory that explains why bidders use all of the above techniques, but it does seem that risk aversion and quite probably the cost of keeping track of auction bids does go a long way to explaining why buyers use fixed price techniques. The reason that they use bargaining as well merits further research.

Perhaps the most exciting frontier of research on the buyer side of the market is the possibility of developing a general econometric model of bidding. Sailer (2006) has developed a model that addresses exit, and Nekipelov (2007) has developed a model that allows for endogenous entry; clearly the next step is to develop parametric and nonparametric models that address both issues simultaneously. Of course as Nekipelov (2007) shows, the equilibria in these models may be hard to find analytically, but his estimation does not require an analytic solution.

These techniques may also be able to help us understand the long standing puzzle of whether feedback matters. If it does not, then rudimentary analysis would suggest eBay should fail; but most estimates have suggested that feedback does not matter. However, as pointed out above, this may be because most analysis assumes that the problem on eBay is adverse selection, not moral hazard. The papers that have checked for moral hazard have generally found a more significant impact from feedback. This hypothesis needs to be more carefully analyzed. It is theoretically possible that with a general structural model of bidding one can directly estimate the cost to a seller from negative feedback. If this was done in several markets, we could finally know how 
well feedback works-which most likely will also provide valuable information for eBay.

In all, eBay seems to be a promising and compelling area for future research, and we look forward to the papers that will almost certainly be appearing soon to address the issues above and other important issues, in part facilitated by the quick availability of market data from eBay. ${ }^{21}$ Since this is a decentralized marketplace with relatively simple and straightforward selling mechanisms, it may be possible to develop a sound theoretic and empirical understanding of how this marketplace works. If a complete understanding of such an important marketplace can be achieved, it would also mean substantial progress in model development.

Acknowledgments The authors wish to thank Editor of the Review of Industrial Organization, Lawrence White, Guest Editor of the Review of Industrial Organization Series on Auctions, Victor Tremblay, and two anonymous referees for their very constructive and helpful suggestions that have greatly improved our paper. We also wish to thank Seda Bülbül Toklu of Rice University for her crucial assistance in helping us in our revision and in authoring the online Appendix B of this paper: "Methodology: Structural Parametric and Nonparametric Methods" in Online Auctions available at http://www.owlnet.rice.edu/ seda.bulbul/.

\section{References}

Abadie, A., Angrist, J., \& Imbens, G. (2002). Instrumental variables estimates of the effects of subsidized training on the quantiles of trainee earnings. Econometrica, 70, 91-117.

Adams, C. P. (2007). Estimating demand from eBay prices. International Journal of Industrial Organization, 25, 1213-1232.

Anderson, S. T., Friedman, D., Milam, G. H., \& Singh, N. (2004). Buy it now: A hybrid internet market institution. UC Santa Cruz economics, working paper no. 565. Retrieved from SSRN: http://ssrn. com/abstract $=533182$.

Andrews, T., \& Benzing, C. (2007). The determinants of price in internet auctions of used cars. Atlantic Economic Journal, 35, 43-57.

Anwar, S., McMillan, R., \& Zheng, M. (2006). Bidding behavior in competing auctions: Evidence from eBay. European Economic Review, 50(2), 307-322.

Ariely, D., Ockenfels, A., \& Roth, A. E. (2005). An experimental analysis of ending rules in internet auctions. RAND Journal of Economics, 36(4), 891-908.

Ariely, D., \& Simonson, I. (2003). Buying, bidding, playing, or competing? Value assessment and decision dynamics. Journal of Consumer Psychology, 13(1\&2), 113-123.

Arnold, B. C., Balakrishnan, N., \& Nagaraja, H. N. (1992). A first course in order statistics. New York: Wiley-Interscience.

Ashenfelter, O. (1989). How auctions work for wine and art. Journal of Economic Perspectives, 3(3), $23-26$.

Athey, S., \& Haile, P. (2007). Nonparametric approaches to auctions. In J. Heckman \& E. Leamer (Eds.), Handbook of econometrics (Vol. 6A, pp. 3847-3965). Amsterdam: Elsevier.

Avery, C. (1998). Strategic jump bidding in english auctions. Review of Economic Studies, 65, 185-210.

Bajari, P., \& Hortaçsu, A. (2003a). Winner's curse, reserve prices and endogenous entry: Empirical insights from eBay auctions. Rand Journal of Economics, 2, 329-355.

Bajari, P., \& Hortaçsu, A. (2003b). Cyberspace auctions and pricing issues, a review of empirical findings. In D. Jones (Ed.), New economy handbook (pp. 163-211). San Diego, CA: Academic Press.

Bajari, P., \& Hortaçsu, A. (2004). Economic insights from internet auctions. Journal of Economic Literature, 42, 457-486.

21 eBay itself sells detailed data on transactions taking place on eBay; see http://developer.ebay.com/ programs/marketdata/ for further information. There are also companies like Terapeak and Hammertab that sell mostly aggregated data that are compiled from eBay's database. 
Balakrishnan, N., \& Rao, C. (1998). Handbook of statistics, vol 16. Order statistics: Theory and methods. Amsterdam: Elsevier.

Bapna, R., Jank, W., \& Shmueli, G. (2008). Consumer surplus in online auctions. Information Systems Research, 19(4), 400-416.

Bierens, H. J., \& Song, H. (2008). Semi-nonparametric estimation of independently and identically repeated first-price auctions via an integrated simulated moments method. Retrieved from Pennsylvania State University: Department of Economics. Web site: http://econ.la.psu.edu/ hbierens/ AUCTIONS_IID.PDF.

Bose, S., \& Daripa, A. (2009). Optimal sale across venues and auctions with a buy-now option. Economic Theory, 38, 137-168.

Brendstrup, B., \& Paarsch, H. J. (2006). Identification and estimation in sequential, asymmetric, english auctions. Journal of Econometrics, 134, 69-94.

Bremzen, A., (2004). Bargain or post the price? Retrieved from new economic school. Web site: http:// www.nes.ru/ abremzen/english/papers.html.

Brisset, K., \& Naegelen, F. (2006). Why the reserve price should not be kept secret. B.E. Press: Topics in Theoretical Economics, 6(1), Article 5.

Bülbül T. S. (2010). A survey of Econometric Methods in Online Auctions. Mimeo.

Cabral, L., \& Hortaçsu, A. (2010). The dynamics of seller reputation: Theory and evidence from eBay. Journal of Industrial Economics, 58, 54-78.

Chakraborty, I., \& Kosmopoulou, G. (2004). Auctions with shill bidding. Economic Theory, 24(2), 271287.

Cohen, A. (2002). The perfect store: Inside eBay. Boston: Little, Brown and Company.

Coppejans, M., \& Gallant, A. R. (2002). Cross-validated SNP density estimates. Journal of Econometrics, $110,27-65$.

Dewally, M., \& Ederington, L. (2002). Reputation, certification, warranties, and information as remedies for seller-buyer information asymmetries: Lessons from the on-line comic book market. Retrieved from University of Oklahoma Price College of Business. Web site: http://faculty-staff.ou.edu/E/ Louis.H.Ederington-1/.

Dewally, M., \& Ederington, L. (2004). What attracts bidders to online auctions and what is their incremental price impact? Retrieved from SSRN: http://ssrn.com/abstract=589861.

Dewan, S., \& Hsu, V. (2004). Adverse selection in electronic markets: Evidence from online stamp auctions. The Journal of Industrial Economics, 52, 497-516.

Diekmann, F., Roe, B. E., \& Batte, M. T. (2008). Tractors on eBay: Differences between internet and in-person auctions. American Journal of Agricultural Economics, 90(2), 306-320.

Donald, S. G., \& Paarsch, H. J. (1993). Piecewise pseudo-maximum likelihood estimation in empirical models of auctions. International Economic Review, 34(1), 121-148.

Eaton, D. H. (2007). The impact of reputation timing and source on auction outcomes. The B.E. Journal of Economic Analysis \& Policy, 7(1), Article 33.

Ely, J. C., \& Hossain, T. (2009). Sniping and squatting in auction markets. American Economic Journal: Microeconomics, 1(2), 68-95.

Engelberg, J., \& Williams, J. (2009). eBay's proxy bidding: A license to shill. Journal of Economic Behavior \& Organization, 72(1), 509-526.

Engelbrecht-Wiggans, R. (1987). On optimal reservation prices in auctions. Management Science, 33(6), 763-770.

Etzion, H., Pinker, E., \& Seidmann, A. (2006). Analyzing the simultaneous use of auctions and posted prices for on-line selling. Manufacturing \& Service Operations Management, 8, 68-91.

Fenton, V. M., \& Gallant, A. R. (1996). Convergence rates of SNP density estimators. Econometrica, 64, 719-727.

Gallant, A. R., \& Nychka, D. W. (1987). Semi-nonparametric maximum likelihood estimation. Econometrica, 55, 363-390.

Gallien, J., \& Gupta, S. (2007). Temporary and permanent buyout prices in online auctions. Management Science, 53, 814-833.

Garratt, R., Walker, M., \& Wooders, J. (2004). Behavior in second-price auctions by highly experienced eBay buyers and sellers. UC Santa Barbara: Department of Economics, UCSB. Retrieved from: http://www.escholarship.org/uc/item/7s72r56p. 
Giray, T., Hasker, K., \& Sickles, R. (2010). Estimating consumer surplus in eBay computer monitor auctions with parametric distributions. Retrieved from Bilkent University Economics Department. Web site: http://www.bilkent.edu.tr/ hasker/Research/giray-hasker-jiang-sickles-09-07-17.pdf.

Gonzalez, R., Hasker, K., \& Sickles, R. (2009). An analysis of strategic behavior in eBay auctions. Singapore Economic Review, 54(2), 1-32.

Gray, S., \& Reiley, D. (2004). Measuring the benefits to sniping on eBay: Evidence from a field experiment. Working paper. University of Arizona. Retrieved from http://econ.arizona.edu/faculty/ workingpapers.asp\#2007.

Haile, P., \& Tamer E. (2000). Inference with an incomplete model of english auctions. University of Wisconsin, SSRI working paper no. 2018. Retrieved from http://ssrn.com/abstract=241133 or doi:10.2139/ssrn.241133.

Haile, P., \& Tamer, E. (2003). Inference with an incomplete model of english auctions. Journal of Political Economy, 111(1), 1-50.

Harris, M., \& Raviv, A. (1981). A theory of monopoly pricing schemes with demand uncertainty. American Economic Review, 71, 347-365.

Hasker, K., Jiang, B., \& Sickles, R. (2010). Estimating consumer surplus in eBay computer monitor auctions. Working Paper.

Häubl, G., \& Popkowski Leszczyc, P. T. L. (2003). Minimum prices and product valuations in auctions. Marketing Science Institute Reports, 3(03-117), 115-141.

Hendricks, K., Onur, I., \& Wiseman, T. (2005). Preemption and delay in eBay auctions. Working paper.

Hendricks, K., Porter, R. H., \& Boudreau, B. (1987). Information, returns, and bidding behavior in OCS auctions: 1954-1969. Journal of Industrial Economics, 35(4), 517-542.

Hidvégi, Z., Wang, W., \& Whinston, A. B. (2006). Buy-price english auction. Journal of Economic Theory, 129(1), 31-52.

Hong, H., \& Nekipelov, D. (2009). Efficient local IV estimation of an empirical auction model, mimeo.

Hoppe, T., \& Sadrieh, A. (2006). An experimental assessment of confederate reserve price bids in online auctions. FEMM working papers 07011, otto-von-guericke University Magdeburg, Faculty of Economics and Management. Retrieved from http://www.ww.uni-magdeburg.de/fwwdeka/femm/ a2007_Dateien/2007_11.pdf.

Horstmann, I. J., \& Lacasse, J. (1997). Secret reserve prices in a bidding model with a resale option. American Economic Review, 87, 663-684.

Hossain, T. (2008). Learning by bidding. RAND Journal of Economics, 39(2), 509-529.

Hossain, T., \& Morgan, J. (2006). ...Plus shipping and handling: revenue (Non) equivalence in field experiments on eBay. B.E. Press: Advances in Economic Analysis \& Policy, 6(2), Article 3.

Houser, D., \& Wooders, J. (2006). Reputation in auctions: Theory and evidence from eBay. Journal of Economics and Management Strategy, 15, 353-369.

Jin, G. Z., \& Kato, A. (2006). Price, quality and reputation: Evidence from an online field experiment. RAND Journal of Economics, 37, 983-1004.

Jin, G. Z., \& Kato, A. (2007). Dividing online and offline: A case study. Review of Economic Studies, 74, 981-1004.

Katkar, R., \& Reiley, D. H. (2006). Public versus secret reserve prices in eBay auctions: Results from a pokémon field experiment. Advances in Economic Analysis and Policy, 6(2), Article 7.

Kazumori, E., \& McMillan, J. (2005). Selling online versus live. Journal of Industrial Economics, 53, 543-569.

Kultti, K. (1999). Equivalence of auctions and posted prices. Games and Economic Behavior, 27, $106-113$.

Laffont, J. J., Ossard, H., \& Vuong, Q. (1995). Econometrics of first-price auctions. Econometrica, 63, 953-980.

Lee, H., \& Malmendier, U. (2007). The bidder's curse. NBER working paper no. 13699. Retrieved from http://www.nber.org/papers/w13699.pdf.

Levin, D., \& Smith, J. L. (1994). Equilibrium in auctions with entry. American Economic Review, 54, 585599.

Livingston, J. A. (2005). How valuable is a good reputation? A sample selection model of internet auctions. The Review of Economics and Statistics, 87(3), 453-465.

Lucking-Reiley, D. (2000). Auctions on the internet, what's being auctioned, and how? The Journal of Industrial Economics, 48, 227-252.

Lucking-Reiley, D., Bryan, D., Prasad, N., \& Reeves, D. (2007). Pennies from eBay: The determinants of price in online auctions. The Journal of Industrial Economics, 55, 223-233. 
Mathews, T. (2004). The impact of discounting on an auction with a buyout option: A theoretical analysis motivated by eBay's buy-it-now feature. Journal of Economics (Zeitschrift Fur Nationalokonomie), 81(1), 25-52.

Mathews, T., \& Katzman, B. (2006). The role of varying risk attitudes in an auction with a buyout option. Economic Theory, 27, 597-613.

McAfee, R. P. (1993). Mechanism design by competing sellers. Econometrica, 61, 1281-1312.

McAfee, R. P., \& McMillan, J. (1988). Search mechanisms. Journal of Economic Theory, 44, 99-123.

Meilijson, I. (1981). Estimation of the lifetime distribution of the parts from autopsy statistics of the machine. Journal of Applied Probability, 18, 829-838.

Milgrom, P. R., \& Weber, R. J. (1982). A theory of auctions and competitive bidding. Econometrica, 50(5), 1089-1122.

Moreno, D., \& Wooders, J. (2008). Auctions with heterogenous entry costs. University of Arizona, working paper 08-05.

Myerson, R. B. (1981). Optimal auction design. Mathematics of Operations Research, 6, 58-73.

Nekipelov, D. (2007). Entry deterrence and learning prevention on eBay. Dissertation, Duke University. Retrieved from http://www.cemfi.es/REStour/Nekipelov.pdf.

Ockenfels, A., \& Roth, A. E. (2006). Late and multiple bidding in second price internet auctions: Theory and evidence concerning different rules for ending an auction. Games and Economic Behavior, 55, 297-320.

Ockenfels, A., Reiley, D., \& Sadrieh, A. (2006). Online auctions. In T. J. Hendershott (Ed.), Handbooks in information systems I, handbook on economics and information systems (pp. 571-628). Amsterdam: Elsevier Science.

Paarsch, H. J. (1992). Deciding between the common and private value paradigms in empirical models of auctions. The Econometrics Journal, 51, 191-215.

Peters, M., \& Severinov, S. (2006). Internet auctions with many traders. Journal of Economic Theory, $130,220-245$.

Rama, K., \& Reiley, D. H. (2006). Public versus secret reserve prices in eBay auctions: results from a pokemon field experiment. Advances in Economic Analysis \& Policy, 6(2), Article 7.

Resnick, P., \& Zeckhauser, R. (2002). Trust among strangers in internet transactions: Empirical analysis of eBay's reputation system. In M. R. Baye (Ed.), In the economics of the internet and e-commerce, volume 11 of advances in applied microeconomics (pp. 127-157). Amsterdam: Elsevier Science.

Resnick, P., Zeckhauser, R., Swanson, J., \& Lockwood, K. (2006). The value of reputation on eBay: A controlled experiment. Experimental Economics, 9, 79-101.

Reynolds, S. S., \& Wooders, J. (2009). Auctions with a buy price. Economic Theory, 38(1), 9-39.

Riefa, C. (2008). To be or not to be an auctioneer? Some thoughts on the legal nature of online eBay auctions and the protection of consumers. Journal of Consumer Policy, 31, 167-194.

Riley, J. G., \& Samuelson, W. (1981). Optimal auctions. The American Economic Review, 71(3), 381-392.

Riley, J. G., \& Zeckhauser, R. (1983). Optimal selling strategies: When to haggle, when to hold firm. The Quarterly Journal of Economics, 98, 267-289.

Rosenkranz, S., \& Schmitz, P. W. (2007). Reserve prices in auctions as reference points. The Economic Journal, 117, 637-653.

Roth, A. E., \& Ockenfels, A. (2002). Last-minute bidding and the rules for ending second-price auctions: Evidence from eBay and Amazon auctions on the internet. American Economic Review, 92(4), 10931103.

Sailer, K. (2006). Searching the eBay marketplace. CESifo working paper no. 1848. Retrieved from http://www.ifo.de/pls/guestci/download/CESifo+Working+Papers+2006/CESifo+Working+Papers+ November+2006/cesifo1_wp1848.pdf.

Samuelson, W. F. (1985). Competitive bidding with entry costs. Economics Letters, 17, 53-57.

Shahriar, Q. (2008). Common value auctions with buy prices. San Diego State University, working paper, 08-02. Retrieved from http://www-rohan.sdsu.edu/ econ/f_papers.htm.

Shahriar, Q., \& Wooders, J. (2007). An experimental study of auctions with a buy price under private and common values. University of Arizona, working paper, 07-19. Retrieved from http://econ. arizona.edu/faculty/workingpapers.asp.

Sinha, A. R., \& Greenleaf, E. A. (2000). The impact of discrete bidding and bidder aggressiveness on sellers' strategies in open english auctions: Reserves and covert shilling. Marketing Science, 19(3), 244-265. 
Song, U. (2004). Nonparametric estimation of an eBay auction model with an unknown number of bidders. Working paper. Retrieved from The University of British Columbia, Department of Economics. Web site: http://faculty.arts.ubc.ca/usong/.

Standifird, S., Roelofs, M., \& Durham, Y. (2004). eBay's "buy-it-now" function and the impact on bidder behavior. International Journal of Electronic Commerce, 9(2), 167-176.

Standifird, S., \& Weinstein, M. (2007). The transaction cost economics of market-based exchange: The impact of reputation and external verification agencies. International Journal of the Economics of Business, 13(3), 409-431.

Stryszowska, M. (2005). Late and multiple bidding in simultaneous and overlapping second price internet auctions. CentER discussion paper.

Tung, Y. A., Gopal, R. D., \& Whinston, A. B. (2003). Multiple online auctions. IEEE computer, 88-90.

Vickrey, W. (1961). Counterspeculation, auctions and competitive sealed tenders. Journal of Finance, 16, 8-37.

Vincent, D. R. (1995). Bidding off the wall: Why reserve prices may be kept secret. Journal of Economic Theory, 65(2), 575-584.

Wang, R. (1993). Auctions versus posted-price selling. The American Economic Review, 83, 838-851.

Wilcox, R. T. (2000). Experts and amateurs: The role of experience in internet auctions. Marketing Letters, 11(4), 363-374.

Wilson, R. (1977). A bidding model of perfect competition. The Review of Economic Studies, 44, 511-518.

Wintr, L. (2008). Some evidence on late bidding in eBay auctions. Economic Inquiry, 46(3), 369-379.

Yin, P. L. (2006). Information dispersion and auction prices. Stanford Institute for Economic Policy Research. Working paper no. 02-024. Retrieved from http://papers.ssrn.com/sol3/papers.cfm? abstract_id=690201. 